\title{
Strategic Interaction in Political Competition: Evidence from Spatial Effects across Chinese Cities*
}

\author{
Jihai $\mathrm{Yu}^{\dagger} \quad \mathrm{Li}-\mathrm{An} \mathrm{Zhou}^{\ddagger} \quad$ Guozhong $\mathrm{Zhu}^{\S}$
}

\begin{abstract}
Promotion of local leaders in China is decided by their upper-level governments which evaluate their performance based largely on local economic growth. Such a promotion scheme leads to tournament competition among local government leaders of the same level. We test the hypothesis of tournament competition by studying the spatial effects across Chinese prefectural-level cities. Employing spatial econometrics tools, we document a strong spatial effect for city-level total investment which fuels short-term economic growth. This spatial effect is shown to occur only for cities within the same province, but not for neighboring cities located in different provinces. We also find that within the same province, the spatial effect mainly exists for cities with similar economic ranking but not for cities that are geographically proximate. The spatial effect tends to diminish for city leaders who are close to the end of their political careers. These findings suggest that the spatial effect for investment is driven by strategic interactions among political rivals in tournament competition. We rule out alternative factors, such as economic spillovers and tax competition, as the key drivers of the observed spatial effect.
\end{abstract}

JEL classification: C23; C33; D02; E62; H11; H30; H72; H77; O53

Keywords: Tournament competition, investment, Chinese economy, spatial effect

\footnotetext{
${ }^{*} \mathrm{Yu}$ acknowledges China National Science Foundation (Project no. 71171005, 71322105) for financial support. Zhou acknowledges China National Science Foundation (Project no. 70973004) for financial support. Yu and Zhou also acknowledge the Key Laboratory of Mathematical Economics and Quantative Finance (Peking University) of the Ministry of Education for financial support.

${ }^{\dagger}$ Corresponding author. Guanghua School of Management, Peking University. Email: jihai.yu@gmail.com; Tel: 8610-62760702; fax: 8610-62753624. Address: Room 349, Guanghua School of Management Building \#2, Peking University, Beijing, China 100871.

${ }^{\ddagger}$ Guanghua School of Management, Peking University, zhoula@gsm.pku.edu.cn.

${ }^{\S}$ School of Business, University of Alberta, guozhong@ualberta.ca.
} 


\section{Introduction}

The phenomenal economic growth in China has spawned a large literature that studies the Chinese economy from various perspectives. One distinguished branch of research links this economic growth to tournament competition among local government leaders (Zhou, 2009; Xu, 2011). A key hypothesis from this perspective is that, in order to maximize their chances of political promotion, local government leaders compete against one another in spurring total investment and boosting the growth of the local economy. This GDP-based political competition significantly contributes to the investment-driven high growth of the Chinese economy as a whole.

The theoretical grounding of tournament competition is well summarized in Xu (2011) as possessing two key components - political centralization and economic regional decentralization. With political centralization, higher level officials in the hierarchical political system maintain personnel control over their lower level counterparts, so that the former are able to promote the latter based on their performance. ${ }^{1}$ On the other hand, regional economic decentralization gives local leaders abundant space for maneuver to promote economic growth. Due to economic decentralization, local leaders can seek to leverage local investment by using a number of different instruments. Examples include directly influencing the investment decisions of state-owned enterprises, allocating land and loans from local state-owned banks, using Local Financing Platforms to finance various investments, ${ }^{2}$ and providing pro-business policies and services (e.g. offering tax reductions and subsidies and speeding up the administrative approval of large projects) to attract FDI and investment from other regions in China. Bardhan and Mookherjee (2006) assert that China is the only country in the world where local governments have played a leading role in economic growth. ${ }^{3}$

The goal of our study is to present evidence that local leaders in China indeed engage in tournament competition by strategically leveraging investment. An analysis of such strategic behavior sheds light on at least two prominent features of the Chinese economy. The first is China's much debated high investment rate. According to the National Bureau of Statistics of China, the ratio of total investment over GDP was as high as $48 \%$ in 2012. At the city level, our data show that total investment as a percent of GDP has been increasing steadily since 2000, reaching $47 \%$ in

\footnotetext{
${ }^{1}$ China's local governments have four hierarchical levels: province, prefectural city, county, and township.

${ }^{2}$ Local Financing Platforms refer to government-backed investment companies through which provincial, prefectural and county governments raise funds for the construction of roads, airports, bridges, power plants and other projects. These investment companies typically use land or government assets as collateral to leverage bank loans.

${ }^{3}$ A number of papers specifically study the effects of economic decentralization in China. Examples include Zhang and Zou (1998), Lin and Liu (2002), Feltenstein and Iwata (2005), Jin et al. (2005), and Zhang (2006).
} 
2005, the last year in our sample. Our study highlights the important role of local governments in China's investment-driven economy. The high government-led investment could be a source of large misallocation of capital and loanable fund in China (Hsieh and Klenow, 2009; Song et al., 2011). The second feature is the political business cycle of investment in China - the fluctuations in gross capital formation closely correlate with the timing of Party congresses held every five years, as documented in $\mathrm{Li}$ (2012). Given the fact that Party congresses at both national and local levels often reshuffle government officials, our study demonstrates a deeper link between the political incentives of local leaders and investment fluctuations in China. ${ }^{4}$ Despite its importance, to the best of our knowledge, few empirical studies have touched on the strategic behavior of Chinese local leaders in investment, and we aim to fill this gap in the literature.

We study prefectural-level city total investment, and identify three clear patterns of spatial correlation. The first is a border effect. We find a strong spatial correlation among cities within the same province, but little correlation for cities that are geographically proximate but belong to different provinces. The second pattern is a GDP ranking effect. Within the same province, the spatial effect mainly exists among cities with similar rankings of per capita GDP, but not among geographical neighbors. The third is an age-of-leader effect. We find that spatial effect is much weaker among leaders whose are near their mandatory retirement age.

These main findings reflect three key features of China's performance-based promotion system. First, the promotion of prefectural-level city leaders is decided by the provincial government, which means that only city leaders in the same province are political rivals for promotion and they do not compete with city leaders from other provinces. Second, in order to level the playing field, a relative performance evaluation is conducted among political peers in prefectural-level cities with similar economic potential. In other words, geographical neighbors, even within the same province, are not proper rivals. Finally, due to the mandatory retirement age, local leaders face a finite horizon planning problem. Since the chance of promotion is almost zero when they are near the age limit, they have little incentive to engage in tournament competition.

Concerns might arise that spatial correlation of investment observed in our data might be caused by factors other than tournament competition, such as an economic spillover effect. To address these concerns, we argue that the alternative explanations are not consistent with all the observed patterns, especially the age-of-leader effect. Nevertheless, additional tests are conducted to further

\footnotetext{
${ }^{4}$ Such political business cycle stems from a very different institutional background than the one studied in Hibbs (1977) and the ensuing research.
} 
rule out this alternative explanation. In summary, the combined results strongly support the view that the documented spatial effect of total investment is a result of strategic behavior of local government leaders in tournament competition.

It is worthwhile to compare the tournament competition among local leaders in China with Western style yardstick competition as studied in Besley and Case (1995) and the ensuing literature. In both cases, competition involves assessment of relative performance, but in very different ways. The assessment of relative performance in yardstick competition is done by voters, reflecting the bottom-up power structure in a democratic society; while the tournament competition in China is based on a top-down power structure in which a higher-level authority picks a winner from a set of political contestants. ${ }^{5}$ The difference in power structure also relates to constraints that the contestants face. China's local leaders have a larger capacity to influence the local economy and react strategically to their political rivals than their counterparts in a democratic regime, because the latter have limited discretion in their investment behavior due to checks and balance from the legislature. Another difference is the assumed information structure. Yardstick competition assumes that voters are poorly-informed about the ability or efforts of the incumbent politicians, so they have to rely on the policies and outcomes of neighboring states or cities as benchmarks. On the other hand, tournament competition assumes that the higher-level authorities have sufficient information about the economic performance of their subordinates, which is a realistic assumption given the hierarchical system in China. A perhaps more important difference is that, in tournament competition, only the performance of contestants within the tournament (cities in the same province in our case) and not the performance of neighbors outside the tournament (e.g. cities sharing a common border but from different provinces) will be compared. This is one of the main sources of evidence for the strategic behavior of local leaders in China.

Our paper is closely related to three strands of literature. The first strand of literature discusses the link between promotion of a local government official (cadre) and the economic performance of the city under his/her administration, examples include Li and Zhou (2005), Chen et al. (2005), $\mathrm{Xu}$ (2011), and Choi (2012). Along this line of research, three papers are closely related to the interpretation of our empirical findings. First, Maskin et al. (2000) document a significantly positive correlation between the change in rank in provincial GDP growth and the change in political status of provincial leaders during 1976-1986. Thus local leaders are likely to engage in

\footnotetext{
${ }^{5}$ For Chinese villages that have undergone transitions to democracy, Agostini et al. (2010) finds evidence of yardstick competition similar to that in a mature democracy but at a lower magnitude.
} 
regional tournament competition in which relative performance is critical. Second, Wu et al. (2013) show evidence that city spending on transportation infrastructure correlates strongly with real GDP growth and that a higher GDP growth rate is related to better odds of promotion for local leaders. But higher city-level environmental investment is uncorrelated with odds of promotion. The third paper is Zheng et al. (2014) which shows that environmental performance positively affects a city leader's probability of being promoted, but the marginal effect is of a much lower scale compared to that of GDP growth. These empirical observations are complementary to our finding that the total investment of one city has a strong spatial effect on the others within the same province but education expenditure does not. While most existing studies demonstrate how promotion of Chinese local leaders is performance-based, our unique contribution to this literature is that we show evidence about how local leaders respond strategically to the behavior of their political rivals given the performance-based promotion scheme.

The second strand of literature uses spatial econometrics models to study strategic interactions. ${ }^{6}$ Our paper differs from this line of literature in two respects. First, we link the spatial effect with a unique feature of the Chinese political system - tournament competition among city leaders. As previously discussed, tournament competition is a critical incentive mechanism for Chinese local leaders and produces important consequences for the Chinese economy. Our study offers a new angle to reinterpret spatial effects in China, as documented in previous literature in light of yardstick competition (e.g., Caldeira, 2012; Zheng et al., 2013). Second, we use the estimation method for a dynamic spatial panel model developed in Lee and Yu (2014). This method allows multiple definitions of neighbors (e.g. two spatial weights matrices), and hence represents a more general specification. We employ this method to test the relative importance of economic distance versus geographical distance and identify the nature of competitors, which is not feasible using traditional models with only one spatial weights matrix.

The third strand is the literature of subnational competition that uses border effects to identify fiscal competition and political competition. Cassette et al. (2012) shows that local governments along the Rhine valley choose business tax rate based on those of their domestic neighbors, but not based on neighbors across the national borders. This is similar to our findings that spatial effect of investment exists among neighbors within a province, but does not exist between neighbors across

\footnotetext{
${ }^{6}$ On the theoretical side, Breuckner (2003) offers an overview, and Devereux et al. (2007, 2008) provide a utility maximization approach to derive the estimation equation for the tax competition. Static models are most common in the empirical literature. Examples include Case et al. (1993), Brueckner (1998), Bordignon et al. (2003), Fredriksson et al. (2004), Baicker (2005), Devereux et al. (2008), Revelli and Tovmo (2007), Devereux et al. (2007), Caldeira (2012), and Zheng et al. (2013).
} 
the provincial borders. Researchers generally find that for regions within a country, cross border fiscal competition exists. See Eugster and Parchet (2013), Geys and Osterloh (2013), Janeba and Osterloh (2013), Parchet (2014), and Agrawal (2015).

The rest of the paper is organized as follows. Section 2 discusses the theoretical and institutional background that leads to tournament competition. Section 3 introduces the empirical specifications and data. Basic empirical results are presented in Section 4. Section 5 further discusses the link between spatial effects and tournament competition. Section 6 briefly concludes.

\section{A Simple Model and Three Hypotheses}

Our main goal is to empirically test whether the total investment of one city responds strategically to that of the others. In this section, we lay out a simple model to clarify the mechanisms that lead to strategic interaction among city leaders. Based on the model, we present three hypothesis that will be tested using city level data.

\subsection{A City Leader's Optimization Problem}

Let $s_{i, t}$ be the political status of the leader in the $i^{t h}$ city with age $t$, then $u\left(s_{i, t}\right)$ denotes the utility for the leader. As discussed in the introduction, local leaders care about their political status and have incentives to leverage total investment in order to increase their chances of promotion. We capture this by assuming that political status has the following law of motion

$$
s_{i, t+1}=s_{i, t}+\rho_{t}\left(y_{i, t}-\lambda \bar{y}_{-i}\right)
$$

where $\rho_{t} \in[0,1)$ is a scaling parameter, $y_{i, t}$ is the investment of the $i^{t h}$ city whose leader is aged $t$, and $\bar{y}_{-i}=\sum_{j \neq i} w_{i j} y_{j, t}$ is the average level of investment of rivals for the $i^{t h}$ city, weighted by $w_{i j}$ which is the importance city $j$ perceived by city $i$ as its competitor. Notice that $\bar{y}_{-i}$ has no age subscript, because the competitors have different ages.

Equation (1) says that the rise of political status for a leader of age $t+1, s_{i, t+1}-s_{i, t}$, depends on his/her investment level relative to the competitors one period earlier. This is because of the unique situation in China: (i) investment is a major driver of GDP growth; (ii) for local leaders, chances of promotion increase with the GDP growth of his/her own city relative to rivals.

The scaling parameter $\rho_{t}$ is age-dependent, and it should be interpreted as the probability of promotion at age $t$, unconditional on the city's investment performance. From the data, this unconditional probability decreases sharply after a certain cutoff age, 53 for party secretaries and 
55 for city mayors. Before the cutoff age, the probability of promotion shows little correlation with age. $^{7}$

On the other hand, costs will exist for leaders for engaging in investment leveraging, because they need to incur personal costs (e.g., time) and make efforts to deal with issues like damage to the environment, potential reduction of future economic growth and other concerns. We use $v\left(y_{i, t}\right)$ to denote the cost associated with investment level $y_{i, t}$. The benefits and costs of investment leveraging for leaders with age $t$ are summarized in the following optimization problem:

$$
\max _{y_{i, \tau}} \sum_{\tau=t}^{T} \beta^{\tau}\left[u\left(s_{i, \tau}\right)-\xi_{i, t} v\left(y_{i, \tau}\right)\right],
$$

subject to equation (1). Here $\beta$ is the discount factor, and $T$ is the time of mandatory retirement for a local leader. $\xi_{i, t}$ is the random shock to disutility function. For example, an outstanding entrepreneur may emerge in the $i^{\text {th }}$ city, which reduces the cost of investment leveraging, leading to a $\xi_{i, t}$ that is smaller than its mean.

Usual assumptions about utility/disutility functions apply here, namely,

$$
\begin{array}{ll}
u^{\prime}(.)>0, & u^{\prime \prime}(.)<0, \\
v^{\prime}(.)>0, & v^{\prime \prime}(.) \geq 0 .
\end{array}
$$

The efforts of local leaders have nondecreasing marginal costs. These assumptions ensure that the optimization problem is well-defined with interior solutions.

A city takes $\bar{y}_{-i}$ as given, and the optimal investment level for government leaders is determined by the following first order condition. To simplify the notation, we omit the subscript $i$ in the equations below.

$$
\xi_{t} \cdot v^{\prime}\left(y_{t}\right)=\rho_{t} \sum_{\tau=t+1}^{T} u^{\prime}\left(s_{\tau}\right)
$$

From the first order condition, we can derive the following partial derivatives

$$
\begin{aligned}
\frac{\partial y_{t}}{\partial \xi_{t}} & =\frac{v^{\prime}\left(y_{t}\right)}{\rho_{t}^{2} \sum_{\tau=t+1}^{T} \beta^{\tau-t} u^{\prime \prime}\left(s_{\tau}\right)-\xi_{\tau} v^{\prime \prime}\left(y_{t}\right)}<0 \\
\frac{\partial y_{t}}{\partial \bar{y}} & =\frac{\lambda \rho_{t}^{2} \sum_{\tau=t+1}^{T} \beta^{\tau-t} u^{\prime \prime}\left(s_{\tau}\right)}{\rho_{t}^{2} \sum_{\tau=t+1}^{T} \beta^{\tau-t} u^{\prime \prime}\left(s_{\tau}\right)-\xi_{\tau} v^{\prime \prime}\left(y_{t}\right)}>0
\end{aligned}
$$

\footnotetext{
${ }^{7}$ The evidence will be presented in Section 4.2 .
} 
where the inequalities hold because $u^{\prime \prime}()<$.0 and $v^{\prime \prime}() \geq$.0 . Therefore, for a given city, the investment level decreases with its leader's disutility shock, but increases with the investment level of its competitors.

\subsection{Spatial Effect}

It is convenient to assume the mean of random shock $\xi_{i, t}$ is one. In the case of $\xi_{i, t}=1$ for each city, it is straightforward to show that a steady state equilibrium exists in which (i) each city takes $\bar{y}_{-i}$ as given, and chooses $y_{i, t}$ that satisfies equation (5), and (ii) for any city, the perceived average investment of rivals equals the actual investment. Obviously, no strategic interaction can be observed in the steady state.

Now suppose the $i^{\text {th }}$ city receives a shock $\xi_{i, t}<1$ which means the disutility of investment leveraging becomes smaller, then a strategic interaction occurs which leads to co-movement of total investment among rival cities. From equation (6), it is clear that city $i$ should increase its total investment. When $y_{i, t}$ is increased, according to equation (7), city $j$ should also increase its investment because $\bar{y}_{-j}$ which contains $y_{i, t}$ is now higher. This in turn motivates cities other than $j$, including city $i$, to increase investment. This escalation of investment continues until the economy reaches a new steady state equilibrium.

As a simple example, we consider the optimization problem of a leader aged $T-1$. Since this leader has only one more period before him/her, his/her investment decision affects promotion probability only once, the first order equation becomes

$$
\xi_{i, T-1} \cdot v^{\prime}\left(y_{i, T-1}\right)=\rho_{T-1} \beta u^{\prime}\left(s_{i, T-1}+\rho_{T-1}\left(y_{i, T-1}-\lambda \bar{y}_{-i}\right)\right)
$$

This is essentially a one-period problem, therefore we omit the age subscript in what follows. We take the exponential form for utility function $u($.$) and assume a linear form for disutility v($.$) . That$ is

$$
u\left(s_{i}+\rho\left(y_{i}-\lambda \bar{y}_{-i}\right)\right)=-e^{-\left(s_{i}+\rho\left(y_{i}-\lambda \bar{y}_{-i}\right)\right)}, \quad v\left(y_{i}\right)=y_{i}
$$

Then the first order condition in equation (8) becomes

$$
\xi_{i}=\rho \beta e^{-\left(s_{i}+\rho\left(y_{i}-\lambda \bar{y}_{-i}\right)\right)}
$$

Take the logarithm of both sides of equation (9), and define $\epsilon_{i}=-(1 / \rho) \log \left(\xi_{i}\right)$, we have

$$
y_{i}=\frac{1}{\rho}\left(\log \beta \rho-s_{i}\right)+\lambda \sum_{j \neq i} w_{i j} y_{j}+\epsilon_{i}
$$


Equation (10) is a basic equation that describes the strategic interaction in a tournament competition. The parameter $\lambda$ measures the degree of strategic interaction among competitors which depends critically on the assumption that $u^{\prime}()>$.0 . That is, a leader's action must affect his/her chance of promotion. Some types of investment (e.g. education investment) do not boost economic growth in the short run. In this case $u^{\prime}()=$.0 , and the model predicts that leaders do not respond to the actions of neighbors at all. We will test this prediction in Section 5. Similarly, if a leader's neighbor is not his rival in the political competition, this leader will not respond to his neighbor's action. In what follows, we will derive three testable hypotheses combining the model with China's institutional arrangements.

\subsection{Three Key Hypotheses About Spatial Effect}

From the optimization problem, we have shown that spatial effect of city-level investment exists provided that a city leader's chance of promotion depends on the city's economic performance relative to other cities. In this subsection, we further discuss three features of the spatial effect that arise from the unique institutional arrangements in China. ${ }^{8}$

Hypothesis 1 (Border Effect): The spatial effect should be confined within the province border.

This hypothesis arises because the personnel evaluation of city leaders is made by the provincial government in China. Since 1984, China's personnel management has moved from two-level-down appointment to one-level-down appointment. Before 1984, the central government evaluated and appointed province and prefecture (city) level leaders. After 1984, the central government controls the appointment of provincial level leaders only, and the provincial government evaluates prefectual level leaders in the province. In other words, each province can be regarded as a separate political market for city leaders after 1984 and the mobility of city leaders across provinces should be very rare. This claim is also verified by our data: during 2000-2005, among a total of 719 city party chiefs and 749 city mayors in our sample, there were only 15 party chiefs and 6 city mayors moving directly to other provinces. The separation of the political market implies that the leader of a city must respond to the investment behavior of his/her rivals in the same province, but may not respond to that of the cities in other provinces.

\footnotetext{
${ }^{8}$ It should be noted that the proposed features can not be derived directly from the optimization model without further assumptions about institutional arrangements. We are grateful to an anonymous referee for pointing this out.
} 
Hypothesis 2 (GDP Ranking Effect): The spatial effect should be stronger among cities with similar ranking of per capita GDP.

In order to make tournament competition work more effectively, players should be placed in the right reference group. In China, GDP growth is a key performance indicator for personnel evaluation, and how to advance the GDP ranking becomes a central concern of local leaders. Thus regions with similar GDP ranking are most likely the close rivals in this competition. There is a lot of media coverage in China about how cities with similar GDP ranking in the same province fiercely compete with each other. For example, It was reported that as the central government initiated the grand plan of "Northeastern Revival" in 2003, Shenyang and Dalian, the two most developed cities in Liaoning province, intensified their economic race for the "dragon head" of the province. ${ }^{9}$ Jiujiang and Ganzhou, the two cities with similar GDP ranking in Jiangxi province, has been engaged in a race for No.2 City in Jiangxi province given the fact that Nanchang, the provincial capital, is undoubtedly the No.1 city with the largest GDP size. ${ }^{10} \mathrm{Xu}(2005)$ reveals that city of Changzhou started to promote aggressive expansion of a private steel producer in violation of the central government regulation, in response to the intensified GDP competition from Nantong which is its main rival city within Jiangsu province.

Hypothesis 3 (Age-of-Leader Effect): The spatial effect should be weaker among cities led by older leaders.

This hypothesis is based on the observation that old city leaders face lower chance of promotion. Figure 2 clearly shows that after certain cutoff age (50 for party chiefs and 55 for mayors), the chance of promotion declines with age but the chance of termination increases with age. ${ }^{11}$ This data feature is captured by the coefficient $\rho_{t}$ in the simple model.

\footnotetext{
9 "Rivaling for the Dragon Head and the Center of Growth Pole: A Tale of Two Cities, Shenyang vs. Dalian", The 21st Century Economic Report, February 22, 2005.

10 "Jiujiang PK Ganzhou: Which City is the No.2 City in Jiangxi Province?", The Jiangnan City News, March 18, $200 \%$.

${ }^{11}$ As pointed out by an anonymous referee, provinces presumably do not want to appoint someone who can only serve for a short period of time.
} 
With some algebra, one can derive the following from equation (6) and (7):

$$
\frac{d\left(\partial y_{t} / \partial \xi_{t}\right)}{d \rho_{t}}<0 ; \quad \frac{d\left(\partial y_{t} / \partial \bar{y}\right)}{d \rho_{t}}>0
$$

In other words, the gradients of both $\partial y_{t} / \partial \xi_{t}$ and $\partial y_{t} / \partial \bar{y}$ increase with $\rho_{t} \cdot{ }^{12}$ Since $\rho_{t}$ decreases with age sharply after some cutoff ages, the prediction is that spatial correlation should decline as a leader approaches or passes the cutoff age.

This age-of-leader effect might also be caused by other incentive issues independent of Chinaspecific institutional arrangements. For example, at younger ages, a leader's effort can benefit multiple periods in the future; while in the last period of his/her career, it can only benefit one period. Therefore, older age leaders are less responsive to competitors. Alesina, Troiano and Cassidy (2015) also shows that, due to longer political career in front of them, younger politicians in Italy are more likely to behave strategically than older politicians.

If we further decompose a leader's competitors into two groups, one younger and the other older, then the spatial correlation of an old leader (the $i^{\text {th }}$ one) with other old competitors should be the weakest, because the lower $\partial y_{t} / \partial \bar{y}$ applied to the response of both the $i^{\text {th }}$ leader and its competitors, hence the self-reinforcing escalation mechanism of investment is greatly weakened.

\section{Empirical Specifications and Data}

\subsection{Empirical Specifications}

Spatial econometrics models study how the behavior of an economic agent depends on the behavior of his/her "neighbors" - other contemporaneous agents. We expand equation (10) with the time dimension, so that the economic activity of agent $i$ at time $t$, denoted by $y_{i t}$, is regressed on the weighted sum of the activity of all other agents, $\sum_{j \neq i}^{n} w_{i j} y_{j t}$, together with a set of control variables. Analogous to time lags in time series analysis, we call the term $\sum_{j \neq i}^{n} w_{i j} y_{j t}$ spatial lag. When only one spatial lag is included, the model is a first order spatial model. A higher order model refers to the case with multiple spatial lags, each with differently defined weights $w_{i j}$. We use both first order and high order models in the analysis.

First Order Spatial Models

\footnotetext{
${ }^{12}$ Recall that $\partial y_{t} / \partial \xi_{t}<0$, hence $\frac{d\left(\partial y_{t} / \partial \xi_{t}\right)}{d \rho_{t}}<0$ implies that the gradient increases with $\rho_{t}$.
} 
The first order spatial model is specified as follows:

$$
y_{i t}=\gamma y_{i, t-1}+\lambda \sum_{j \neq i}^{n} w_{i j} y_{j t}+x_{i t}^{\prime} \beta+z_{p t}^{\prime} \delta+\eta_{i}+\alpha_{t}+\epsilon_{i t},
$$

where $y_{i t}$ is total investment or other economic variables of interest. We include $y_{i, t-1}$ in the regressor to allow for a dynamic effect, which can be considered as a measure of policy inertia or policy stability. An individual (city) effect $\eta_{i}$ captures regional differences in resource endowment, cultural characteristics and other factors. Time effect $\alpha_{t}$ captures both macro shocks and macro policy effects for each period. The omission of these shocks and policy effects can lead to spurious spatial effects.

We control for a set of prefectural-level city variables $x_{i t}$ that vary over time. They are account balance, fiscal population (i.e., the number of public empolyees whose wage bills come from the government budget), GDP per capita, manufacturing ratio, fiscal revenue and transfer payment from the upper-level government. Definitions of these variables are provided in Appendix A.

We also include a set of province level control variables $z_{p t}$ that are time-variant in the regression. They are province level fiscal revenue, fiscal expenditure, public capital investment, transfer payment, general purpose transfer payment and account balance, with definitions given in Appendix A. Including these variables in the regression controls for a potential spatial effect driven by policy shocks initiated by the province level government. For example, positive spatial correlation in investment among cities within the same province might arise due to the construction of a highway within a province, or the increase of transfer payments from provincial government to prefectures. Such correlation should be differentiated from spatial effects driven by strategic interaction as predicted in our simple model in Section 2. In particular, an important source of identification in this paper is that spatial correlation of investment is found among same-province cities, but not cross-province cities, hence it is necessary to control for province specific factors. In addition, economic heterogeneity across provinces is significant in China, which is emphasized in studies such as Kanbur and Zhang (2005) and Fan et al. (2013). This also necessitates controlling for province-specific variables.

\section{High Order Spatial Models}

A high order spatial model allows multiple spatial lags. Technically it uses more than one spatial weights matrix, which essentially allows multiple ways of defining neighbors. For example, 
the regression equation for a second order model is

$$
y_{i t}=\gamma y_{i, t-1}+\lambda_{1} \sum_{j \neq i}^{n} w_{1, i j} y_{j t}+\lambda_{2} \sum_{j \neq i}^{n} w_{2, i j} y_{j t}+x_{i t}^{\prime} \beta+z_{p t}^{\prime} \delta+\eta_{i}+\alpha_{t}+\epsilon_{i t} .
$$

This second order model is used to study the relative importance of economic and geographical neighbors, as well as the relative importance of neighbors within and across provinces.

In both first order and high order spatial models, we employ a two-stage least square (2SLS) estimation in which the neighboring values of control and predetermined variables are used as instruments for the endogenous spatial lag term. As in the dynamic panel data literature, each city's own control and predetermined variables are used to instrument the lagged values after the elimination of individual effects. To handle the Nickell bias problem (Nickell 1981) due to the manycity effects, we use instruments after the forward orthogonal difference (FOD) transformation as in Alvarez and Arellano (2003). ${ }^{13}$

The disturbance $\epsilon_{i t}$ might be spatially correlated. However this does not affect the consistency of 2SLS estimates. To avoid over-specification, we treat the disturbances as i.i.d errors.

\section{Spatial Weights Matrices}

One of the key issues in the above spatial model is the spatial weights matrix, $W_{n}=\left[w_{i j}\right]_{i, j=1}^{n}$. This is an $n \times n$ matrix that defines the relative "distance" between city $i$ and city $j$. Cities with positive weights are called "neighbors" . Neighbors that are presumably more inter-dependent with city $i$ are given more weights. In our estimation we restrict $W_{n}$ to be row-normalized with zeros on the diagonal. This normalization ensures that all the weights are between 0 and 1 and weighting operations can be interpreted as an average of the neighboring values. The coefficient $\lambda$ in the first-order model (or $\lambda_{1}$ and $\lambda_{2}$ in the high order model) measures the strength of spatial effects. Thus it is the key parameter in our study.

We consider two types of neighbors: geographical and economic. The former is based on geographical proximity, denoted by $G^{\text {within }}$ and $G^{\text {across }}$. The latter is based on proximity in the ranking of per capita GDP, denoted by $E^{\text {within }}$ and $E^{\text {across }}$. Because city rivals are relatively stable and will not change year by year, we use the average GDP per capita during our sample to determine the economic neighbors. Here the superscript "within" means the weights matrix treats only cities within the same provinces as neighbors (with positive weights); while "across" means it treats cities in different provinces as neighbors and assigns zero weights to cities in the same

\footnotetext{
${ }^{13}$ See Appendix B for estimation details.
} 
Table 1: A List of Spatial Weights Matrices

\begin{tabular}{|c|c|c|c|}
\hline \multicolumn{2}{|r|}{ Within Province } & \multicolumn{2}{|r|}{ Cross Province } \\
\hline Symbol & Definition of neighbors & Symbol & Definition of neighbors \\
\hline$E^{\text {within }}$ & $\begin{array}{l}\text { two regions } \\
\text { with similar GDP per capita }\end{array}$ & $E^{\text {cross }}$ & $\begin{array}{l}\text { two regions from neighboring provinces } \\
\text { with similar GDP per capita }\end{array}$ \\
\hline$G^{\text {within }}$ & regions in the same province & $G^{\text {cross }}$ & proximate regions outside the province \\
\hline$\widetilde{G}_{1}^{\text {within }}$ & one most proximate region & $\widetilde{G}^{\text {cross }}$ & $\begin{array}{l}\text { proximate regions outside the province } \\
\text { (no mountain) }\end{array}$ \\
\hline$\widetilde{G}_{2}^{\text {within }}$ & two most proximate regions & & \\
\hline
\end{tabular}

Table 2: City Counts for Each Province (330 cities)

\begin{tabular}{|c|c|c|c|c|c|c|c|c|c|}
\hline Anhui & 16 & Fujian & 9 & Gansu & 14 & Guangdong & 21 & Guangxi & 14 \\
\hline Guizhou & 9 & Hainan & 2 & Hebei & 11 & Heilongjiang & 13 & Henan & 17 \\
\hline Hubei & 12 & Hunan & 14 & Inner Mongolia & 12 & Jiangsu & 13 & Jiangxi & 11 \\
\hline Jilin & 9 & Liaoning & 14 & Ningxia & 4 & Qinghai & 8 & Shaanxi & 10 \\
\hline Shandong & 17 & Shanxi & 11 & Sichuan & 21 & Tibet & 7 & Xinjiang & 14 \\
\hline Yunan & 16 & Zhejiang & 11 & & & & & & \\
\hline
\end{tabular}

province. This treatment is suitable for the study of tournament competition in which only the performances of neighbors within the tournament (cities within a province) are compared.

Specifically, given city $i, G^{\text {within }}$ treats as its neighbors all the cities that are in the same province while $E^{\text {within }}$ takes those same-province cities as neighbors whose within-province rankings of GDP per capita are either one place above or below city $i . G^{\text {across }}$ takes as neighbors cities that are not in the same province but share a common border with city $i$. Regarding $E^{a c r o s s}$, for a given city, we choose its neighbors from neighboring provinces whose GDP per capita is either one place above or below. These spatial weights matrices are summarized in the upper rows of Table 1 . They are used in our baseline analysis.

The bottom rows of Table 1 list weights matrices that are used in extended analysis and robustness checks. We use letters with tildes to denote these matrices. $\widetilde{G}^{\text {across }}$ is similar to $G^{\text {across }}$, but it is more stringent in selecting neighbors, as it excludes across-province geographically proximate cities if they are separated by mountains. This is designed to prevent mountains from affecting our estimation of spatial effects. Historically large mountains have severely impeded trade and other economic interactions. $\widetilde{G}_{1}^{\text {within }}$ and $\widetilde{G}_{2}^{\text {within }}$ are designed to refer to rivals within a province. With $\widetilde{G}_{1}^{\text {within }}$, a city has only one neighbor - the city within the same province and geographically most 
proximate to it. Similarly, with $\widetilde{G}_{2}^{\text {within }}$ a city has two neighbors that are within the same province and geographically most proximate.

We have a total number of 330 cities in our sample for the period of 2000-2005. These cities are from 27 provinces (we do not include Beijing, Shanghai, Tianjin, and Chongqing, which are province level cities). Table 2 shows the city counts for each province. We see that each province has a different number of cities. This asymmetry of city numbers will not affect the estimation, and will even be helpful for the $G^{\text {within }}$ setting when each city interacts with all other cities in the same province (see Lee, 2007).

\subsection{Data}

The data are compiled from several sources. The data on city and province level public finances are mainly from Fiscal Statistics of Cities and Counties in China for the period 2000-2005. The yearbook is published by China Financial and Economic Publishing House, a state-owned press under the supervision of the Ministry of Finance of the People's Republic of China. It collects detailed information on city-level fiscal statistics, such as fiscal revenues and expenditures, fiscal account balances, transfer payments, and fiscal population. The yearbook also has province level fiscal data such as fiscal revenue, fiscal expenditure and transfer payment from the central government.

City-level total investment data come from the China City Statistical Yearbook. ${ }^{14}$ Other citylevel economic characteristics, such as manufacturing ratio (the ratio of the value-added of the manufacturing industry over GDP) and GDP per capita, come from the China Statistical Yearbook for Regional Economy. These two yearbooks are published annually by China Statistical Press, a state-owned press under the supervision of the National Bureau of Statistics of China. Table 3 reports summary statistics of the variables that we use in the regression. More detailed descriptions of these variables are available in Appendix A.

We also use information about the city leaders' age and career mobility, collected from Baidu Baike, ${ }^{15}$ which is a large data source that includes the curriculum vitaes of Chinese government leaders.

\footnotetext{
${ }^{14}$ The yearbook does not provide investment information until 2000.

${ }^{15}$ http://baike.baidu.com.
} 
Table 3: Summary Statistics

\begin{tabular}{|c|c|c|c|c|c|c|}
\hline Variable & Measure & Obs. & Mean & $\begin{array}{l}\text { Standard } \\
\text { Deviation }\end{array}$ & Min & Max \\
\hline \multicolumn{7}{|c|}{ Dependent Variables } \\
\hline Total Investment & Billion & 1980 & 13.751 & 19.882 & 0.184 & 187.014 \\
\hline Education Expenditure & Billion & 1980 & 0.588 & 0.511 & 0.006 & 5.098 \\
\hline \multicolumn{7}{|c|}{ City Level Control Variables } \\
\hline Account Balance & Billion & 1980 & 0.301 & 0.705 & -0.514 & 14.000 \\
\hline Fiscal Revenue & Billion & 1980 & 1.941 & 3.290 & 0.014 & 41.000 \\
\hline Fiscal Population & 100000 & 1980 & 1.081 & 0.638 & 0.037 & 3.400 \\
\hline Manufacturing ratio & decimal & 1980 & 0.428 & 0.128 & 0.091 & 0.897 \\
\hline GDP per capita & 10000 & 1980 & 1.104 & 1.412 & 0.115 & 27.213 \\
\hline Transfer Payment & Billion & 1980 & 1.062 & 1.116 & -0.216 & 13.000 \\
\hline \multicolumn{7}{|c|}{ Provincial Government Level Control Variables } \\
\hline Fiscal Revenue & Billion & 1980 & 12.607 & 15.984 & 0.273 & 91.758 \\
\hline Fiscal Expenditure & Billion & 1980 & 17.960 & 19.332 & 0.855 & 116.485 \\
\hline Public Capital Investment & Billion & 1980 & 2.439 & 3.859 & 0.019 & 19.378 \\
\hline Transfer Payment & Billion & 1980 & 6.468 & 5.850 & 0.212 & 32.851 \\
\hline General Purpose Transfer Payment & Billion & 1980 & 0.254 & 0.694 & -0.778 & 3.392 \\
\hline Account Balance & Billion & 1980 & 3.182 & 4.403 & -0.099 & 26.803 \\
\hline
\end{tabular}

\section{Empirical Results}

In this section we show a strong spatial correlation of total investment among cities within the same provinces. Then we present three clear patterns in the spatial correlation: a border effect, GDP ranking effect and age-of-leader effect.

\subsection{Spatial Effect of Total Investment}

Table 4 reports the basic results using a first order spatial model. For now we focus on the within province spatial correlation. The main coefficient of interest is $\lambda$, the spatial effect coefficient. Using either a within-province economic matrix $\left(E^{\text {within }}\right)$ or geographical matrix $\left(G^{\text {within }}\right)$, the estimated $\lambda$ is statistically significant. The point estimates of $\lambda$ are 0.353 and 0.119 respectively. Both are significant at the $1 \%$ level. Thus total investment exhibits a strong and positive spatial correlation, as predicted by the simple optimization model of local leaders. Of course the correlation could also be driven by a spillover effect. In the subsection that follows, some salient features of spatial correlation are documented: each is consistent with the theory of tournament competition, but more or less inconsistent with the alternative theories. 
Table 4: Spatial Correlation From First Order Model

\begin{tabular}{|c|c|c|c|c|}
\hline \multicolumn{5}{|c|}{ Dependent Variable: Investment } \\
\hline & $G^{\text {within }}$ & $E^{\text {within }}$ & $G^{\text {cross }}$ & $E^{\text {cross }}$ \\
\hline Investment of Neighbors & $\begin{array}{c}0.353 \\
(0.048)\end{array}$ & $\begin{array}{c}0.119 \\
(0.027)\end{array}$ & $\begin{array}{l}-0.004 \\
(0.026)\end{array}$ & $\begin{array}{c}0.061 \\
(0.033)\end{array}$ \\
\hline \multicolumn{5}{|l|}{ City Level Controls } \\
\hline Lagged Investment & $\begin{array}{l}-0.004 \\
(0.117)\end{array}$ & $\begin{array}{l}0.795 \\
(0.11)\end{array}$ & $\begin{array}{c}0.26 \\
(0.141)\end{array}$ & $\begin{array}{c}0.972 \\
(0.098)\end{array}$ \\
\hline Account Balance & $\begin{array}{c}11.18 \\
(4.287)\end{array}$ & $\begin{array}{l}6.467 \\
(3.88)\end{array}$ & $\begin{array}{c}7.603 \\
(4.343)\end{array}$ & $\begin{array}{c}4.196 \\
(4.066)\end{array}$ \\
\hline Fiscal Revenue & $\begin{array}{l}59.122 \\
(6.134)\end{array}$ & $\begin{array}{l}18.018 \\
(5.737)\end{array}$ & $\begin{array}{l}49.188 \\
(7.706)\end{array}$ & $\begin{array}{c}9.648 \\
(4.949)\end{array}$ \\
\hline Fiscal Population & $\begin{array}{c}14.044 \\
(22.738)\end{array}$ & $\begin{array}{c}4.317 \\
(20.499)\end{array}$ & $\begin{array}{c}25.302 \\
(23.205)\end{array}$ & $\begin{array}{c}9.614 \\
(21.771)\end{array}$ \\
\hline Manufacturing ratio & $\begin{array}{c}48.305 \\
(39.767)\end{array}$ & $\begin{array}{l}114.269 \\
(34.546)\end{array}$ & $\begin{array}{c}129.675 \\
(39)\end{array}$ & $\begin{array}{c}121.16 \\
(36.641)\end{array}$ \\
\hline GDP per capita & $\begin{array}{l}-125.11 \\
(33.247)\end{array}$ & $\begin{array}{l}-77.742 \\
(31.874)\end{array}$ & $\begin{array}{r}-135.864 \\
(36.052)\end{array}$ & $\begin{array}{l}-47.973 \\
(32.394)\end{array}$ \\
\hline Transfer Payment & $\begin{array}{l}42.275 \\
(6.096)\end{array}$ & $\begin{array}{l}25.815 \\
(5.696)\end{array}$ & $\begin{array}{l}40.576 \\
(6.615)\end{array}$ & $\begin{array}{c}21.383 \\
(5.798)\end{array}$ \\
\hline \multicolumn{5}{|l|}{ Provincial Governments Controls } \\
\hline Fiscal Revenue & $\begin{array}{c}0.19 \\
(1.613)\end{array}$ & $\begin{array}{c}3.184 \\
(1.433)\end{array}$ & $\begin{array}{c}2.412 \\
(1.628)\end{array}$ & $\begin{array}{l}3.842 \\
(1.51)\end{array}$ \\
\hline Fiscal Expenditure & $\begin{array}{l}-0.688 \\
(1.068)\end{array}$ & $\begin{array}{l}-1.477 \\
(0.965)\end{array}$ & $\begin{array}{l}-1.013 \\
(1.103)\end{array}$ & $\begin{array}{l}-1.745 \\
(1.023)\end{array}$ \\
\hline Public Capital Investment & $\begin{array}{l}-12.91 \\
(3.333)\end{array}$ & $\begin{array}{c}-13 \\
(2.998)\end{array}$ & $\begin{array}{r}-14.921 \\
(3.389)\end{array}$ & $\begin{array}{l}-13.05 \\
(3.179)\end{array}$ \\
\hline Transfer Payment & $\begin{array}{l}4.271 \\
1.801\end{array}$ & $\begin{array}{c}5.536 \\
1.6\end{array}$ & $\begin{array}{l}7.107 \\
1.803\end{array}$ & $\begin{array}{c}5.94 \\
1.693\end{array}$ \\
\hline General Purpose Transfer Payment & $\begin{array}{c}-10.431 \\
5.981\end{array}$ & $\begin{array}{c}-5.912 \\
5.502\end{array}$ & $\begin{array}{c}-23.562 \\
6.63\end{array}$ & $\begin{array}{c}-3.187 \\
5.624\end{array}$ \\
\hline Account Balance & $\begin{array}{c}-0.906 \\
1.759\end{array}$ & $\begin{array}{c}-1.923 \\
1.601\end{array}$ & $\begin{array}{l}0.138 \\
1.823\end{array}$ & $\begin{array}{c}-2.616 \\
1.678\end{array}$ \\
\hline
\end{tabular}

This table reports results from the first order spatial model. Each column corresponds to one spatial weights matrix. The numbers in parenthesis are standard errors. Time and city fixed effects are controlled for. The number of observations is 1650 . 
The magnitude of spatial effect is much bigger when economic matrix rather than geographical matrix is used $(\hat{\lambda}=0.353$ as opposed to $\hat{\lambda}=0.119) .{ }^{16}$ If we assume the independence of these two estimates for $\lambda$, then given their small standard errors as reported in Table 4, the difference between the two estimates are statistically significant. This difference is generally significant in further studies below, indicating greater importance of economic ranking than geographic proximity in the tournament competition.

We briefly discuss regression coefficients for the control variables. The coefficient of the dynamic effect (the time lag), $\gamma$, informs us how total investment depends on the previous year's level. This coefficient can be seen as a measure for policy inertia and stability. The point estimates are -0.004 and 0.795 respectively for geographical and economic neighbors, falling far below one, thereby suggesting that total investment has a relatively low degree of inertia. Account balance and fiscal revenue have positive effects on total investment. Both variables represent budget constraints of the local government which determine the capacity of local leaders to boost total investment. Manufacturing ratio measures the degree of industrialization in a city. Theoretically a higher level of a city's industrialization requires more investment. This is confirmed by the positive and significant coefficients under different specifications. GDP per capita has a negative impact on total investment, which seems counter-intuitive. Without other control variables, GDP per capita is positively correlated with total investment. However when other attributes, especially fiscal revenue and transfer payment, are controlled for, the correlation between GDP per capita and total investment turns negative. ${ }^{17}$ Transfer payments from upper-level government have strong and statistically significant effects on total investment. Larger transfer payments can significantly relax local governments' budget constraints, so they can engage in more public investment or use fiscal funds to support more private investment.

For the province level variables, we see that public capital investment has a negative effect on cities' total investment, which might indicate a crowding-out effect. The general purpose transfer payment has a positive and significant effect on the total investment. Other province level variables have insignificant impacts on cities' total investment for most model specifications. As mentioned earlier, controlling for province level variables helps us address the concern that the observed spatial effect may be induced by certain policy shocks at the province level, such as universal increases in transfer payments from the provincial government, or investment in the province-wide infrastructure

\footnotetext{
${ }^{16}$ In Agostini et al. (2010), the spatial effects are between 0.11 and 0.2 .

${ }^{17}$ More details about these correlations are available from authors upon request.
} 
funded by the provincial government. We also use lagged values of these variables as an additional control, and the results are qualitatively similar.

\subsection{Patterns of Spatial Effect}

We present three clear patterns of spatial correlation for city level total investment, which provides an empirical test of the three hypotheses proposed in Section 2.

\subsubsection{Border Effect}

So far we have focused on within province spatial correlation, which is statistically significant and economically strong. Turning to across-province cities, we find little spatial correlation in investment. The border effect is evident.

Results based on across-province weights matrices $\left(G^{\text {across }}\right.$ and $E^{\text {across }}$ ) are reported in the right columns of Table 4. Technically, these weights matrices treat prefectural cities as neighbors that are geographically and/or economically proximate, but from different provinces. No spatial effect is found for geographical neighbors. When an economic weights matrix $\left(E^{a c r o s s}\right)$ is used, the spatial effect is statistically significant, but much weaker than the effect among within-province neighbors $(\lambda=0.119$ versus $\lambda=0.061)$.

To further test the border effect, we employ a high order spatial model with two weights matrices, one for within province neighbors and the other for across province neighbors. This is a more general specification which helps avoid potential omitted variable bias. We investigate the following combinations of weights matrices: (i) geographical neighbors within and across provinces $\left(G^{\text {within }}\right.$ and $\left.G^{\text {across }}\right)$; (ii) economic neighbors within and across provinces ( $E^{\text {within }}$ and $\left.E^{\text {across }}\right) .{ }^{18}$ By putting within- and across-province neighbors together, we study whether the interactions of total investment are indeed confined within a province's border.

Table 5 reports the results. Based on either geographical or economic neighbors, spatial effects are strictly confined within a province. In the case of geographical neighbors, the coefficient for $G^{\text {within }}$ is 0.382 with standard error 0.036 , but the coefficient for $G^{\text {across }}$ is -0.034 with standard error 0.022 which is insignificant. For economically-defined neighbors within and across provinces ( $E^{\text {within }}$ and $E^{\text {across }}$, we again find a strong within-province spatial effect, with the scales close to those from the first order regressions. However, we find little across-province spatial effect (a point

\footnotetext{
${ }^{18}$ To have a robustness check, we also try four regions from neighboring provinces. Results, available from authors upon request, are qualitatively similar.
} 
Table 5: Spatial Correlation: Border Effect

\begin{tabular}{lcc}
\hline \hline \multicolumn{1}{c}{ Dependent Variable: } & $\begin{array}{c}\text { Investment } \\
G^{\text {within }}\end{array}$ & $E^{\text {within }}$ \\
& and $G^{\text {cross }}$ & and $E^{\text {cross }}$ \\
\hline Investment of Neighbors (within) & 0.382 & 0.142 \\
& $(0.036)$ & $(0.026)$ \\
Investment of Neighbors (across) & -0.034 & 0.003 \\
& $(0.022)$ & $(0.03)$ \\
City Level Controls & & \\
\hline Lagged Investment & & \\
Account Balance & 0.269 & 0.896 \\
& $(0.078)$ & $(0.077)$ \\
Fiscal Revenue & 9.757 & 6.272 \\
Fiscal Population & $(3.881)$ & $(3.856)$ \\
& 44.335 & 12.014 \\
Manufacturing ratio & $(4.3)$ & $(3.983)$ \\
& 7.318 & 0.373 \\
GDP per capita & $(20.745)$ & $(20.603)$ \\
& 40.827 & 111.409 \\
Transfer Payment & $(35.937)$ & $(34.704)$ \\
& -89.245 & -66.91 \\
Fransfer Payment & $(29.624)$ & $(30.149)$ \\
Provincial Government Controls & 35.402 & 23.027 \\
Fiscal Revenue & $(5.327)$ & $(5.325)$ \\
& & \\
Account Balance & 0.907 & 3.324 \\
& $(1.454)$ & $(1.425)$ \\
& -1.185 & -1.564 \\
& $(0.979)$ & $(0.965)$ \\
& -12.087 & -12.615 \\
& $(3.043)$ & $(3.009)$ \\
& 3.672 & 5.218 \\
& $(1.639)$ & $(1.607)$ \\
& -1.959 & -2.431 \\
& $(5.403)$ & $(5.232)$ \\
& -1.951 & -2.326 \\
& & $(1.583)$ \\
\hline
\end{tabular}

This table reports results from the second order spatial model where both within province and cross province weights matrices are included in the same regression equation. The numbers in parenthesis are standard errors. Time and city fixed effects are controlled for. The number of observations is 1650 . 
estimate of 0.003 , with standard error 0.03). Therefore, the high order spatial model shows a clear border effect - total investment exhibits a strong positive spatial effect within a province, but no spatial effect across provinces.

\subsubsection{GDP Ranking Effect}

The simple model in Section 2 predicts that spatial correlation should be stronger among sameprovince cities with similar ranking of per capita GDP. On the other hand, the correlation should be weak among cities that are geographically proximate, because the tournament competition in China is typically based on GDP ranking. To test this prediction, we use the within-province geographical weights matrices $\widetilde{G}_{1}^{\text {within }}$ and $\widetilde{G}_{2}^{\text {within }}$. Recall that a city has only one neighbor based on $\widetilde{G}_{1}^{\text {within }}$, and two neighbors based on $\widetilde{G}_{2}^{\text {within }}$.

Results from the first-order model are reported in the first two columns of Table 6 . Using either $\widetilde{G}_{1}^{\text {within }}$ or $\widetilde{G}_{2}^{\text {within }}$, the coefficient of spatial effect is small, but statistically significant. Thus, although a spatial effect exists among geographically neighboring cities, it has only marginal importance. This conclusion is clearer when the high order model is used.

The high order model puts economic weights matrix $\left(E^{\text {within }}\right)$ together with $\widetilde{G}_{1}^{\text {within }}$ or $\widetilde{G}_{2}^{\text {within }}$. As long as the geographical neighbors are not identical to the economic neighbors for all the cities within a province, we can separate the two types of spatial effects. For the 330 cities in the sample, when using $\widetilde{G}_{1}^{\text {within }}$, there exist only 60 cities (out of 330) that are connected with both geographical and economical neighbors. When using $\widetilde{G}_{2}^{\text {within }}$, we have 147 cities, which is still less than half of the sample. This validates our separation of geographical and economic neighbors.

Results are reported in the last two columns of Table 6 . When the geographical weights matrix $\widetilde{G}_{1}^{\text {within }}$ is combined with the economic weights matrix $E^{\text {within }}$, the coefficient of geographical spatial effect is 0.032 (with standard error 0.019), but the coefficient of economic spatial effect is 0.132 (with standard error 0.024). The spatial effect is about 4 times stronger among economic neighbors than among geographical neighbors.

Now consider the broader definition of geographical neighbors. Based on the combination

of $\widetilde{G}_{2}^{\text {within }}$ and $E^{\text {within }}$, the coefficient of geographical spatial effect is larger and becomes more significant, which is likely due to more overlapping between the two types of neighbors. The coefficient for economic spatial effect is still significantly larger.

In summary, within a province, spatial correlation mainly exists among cities with similar 
Table 6: Spatial Correlation: GDP Ranking Effect

\begin{tabular}{|c|c|c|c|c|}
\hline Depende & $\begin{array}{l}\text { Variable } \\
\widetilde{G}_{1}^{\text {within }}\end{array}$ & $\begin{array}{l}\text { Investment } \\
\widetilde{G}_{2}^{\text {within }}\end{array}$ & $\begin{array}{l}\widetilde{G}_{1}^{\text {within }} \\
\text { and } E^{\text {within }}\end{array}$ & $\begin{array}{c}\widetilde{G}_{2}^{\text {within }} \\
\text { and } E^{\text {within }}\end{array}$ \\
\hline Investment of Neighbors (Geo) & $\begin{array}{c}0.039 \\
(0.023)\end{array}$ & $\begin{array}{c}0.133 \\
(0.031)\end{array}$ & $\begin{array}{c}0.032 \\
(0.019)\end{array}$ & $\begin{array}{c}0.095 \\
(0.023)\end{array}$ \\
\hline Investment of Neighbors (Econ) & - & - & $\begin{array}{c}0.132 \\
(0.024)\end{array}$ & $\begin{array}{c}0.135 \\
(0.024)\end{array}$ \\
\hline \multicolumn{5}{|l|}{ City Level Controls } \\
\hline Lagged Investment & $\begin{array}{c}0.674 \\
(0.127)\end{array}$ & $\begin{array}{c}0.366 \\
(0.137)\end{array}$ & $\begin{array}{c}0.749 \\
(0.086)\end{array}$ & $\begin{array}{c}0.608 \\
(0.083)\end{array}$ \\
\hline Account Balance & $\begin{array}{c}5.372 \\
(3.962)\end{array}$ & $\begin{array}{c}7.126 \\
(3.995)\end{array}$ & $\begin{array}{c}6.84 \\
(3.775)\end{array}$ & $\begin{array}{c}7.728 \\
(3.696)\end{array}$ \\
\hline Fiscal Revenue & $\begin{array}{l}26.392 \\
(6.679)\end{array}$ & $\begin{array}{l}41.164 \\
(7.109)\end{array}$ & $\begin{array}{c}19.39 \\
(4.485)\end{array}$ & $\begin{array}{l}25.807 \\
(4.294)\end{array}$ \\
\hline Fiscal Population & $\begin{array}{c}13.849 \\
(21.198)\end{array}$ & $\begin{array}{c}19.132 \\
(21.313)\end{array}$ & $\begin{array}{c}2.864 \\
(20.102)\end{array}$ & $\begin{array}{c}4.815 \\
(19.682)\end{array}$ \\
\hline Manufacturing ratio & $\begin{array}{l}115.442 \\
(35.92)\end{array}$ & $\begin{array}{c}95.79 \\
(36.365)\end{array}$ & $\begin{array}{l}106.612 \\
(34.158)\end{array}$ & $\begin{array}{c}92.379 \\
(33.611)\end{array}$ \\
\hline GDP per capita & $\begin{array}{l}-82.721 \\
(32.913)\end{array}$ & $\begin{array}{l}-120.751 \\
(33.706)\end{array}$ & $\begin{array}{l}-83.643 \\
(29.882)\end{array}$ & $\begin{array}{c}-101.312 \\
(29.175)\end{array}$ \\
\hline Transfer Payment & $\begin{array}{c}28.733 \\
(5.98)\end{array}$ & $\begin{array}{l}35.085 \\
(6.058)\end{array}$ & $\begin{array}{l}26.324 \\
(5.279)\end{array}$ & $\begin{array}{l}28.856 \\
(5.129)\end{array}$ \\
\hline \multicolumn{5}{|l|}{ Provincial Government Controls } \\
\hline Fiscal Revenue & $\begin{array}{c}3.204 \\
(1.481)\end{array}$ & $\begin{array}{c}2.047 \\
(1.509)\end{array}$ & $\begin{array}{c}2.922 \\
(1.399)\end{array}$ & $\begin{array}{c}2.28 \\
(1.374)\end{array}$ \\
\hline Fiscal Expenditure & $\begin{array}{l}-1.452 \\
(0.997)\end{array}$ & $\begin{array}{l}-1.081 \\
(1.003)\end{array}$ & $\begin{array}{l}-1.383 \\
(0.944)\end{array}$ & $\begin{array}{l}-1.21 \\
(0.924)\end{array}$ \\
\hline Public Capital Investment & $\begin{array}{l}-12.288 \\
(3.055)\end{array}$ & $\begin{array}{c}-12.008 \\
(3.065)\end{array}$ & $\begin{array}{l}-11.383 \\
(2.893)\end{array}$ & $\begin{array}{l}-10.937 \\
(2.835)\end{array}$ \\
\hline Transfer Payment & $\begin{array}{c}6.387 \\
(1.648)\end{array}$ & $\begin{array}{c}6.207 \\
(1.655)\end{array}$ & $\begin{array}{c}5.301 \\
(1.573)\end{array}$ & $\begin{array}{c}5.079 \\
(1.541)\end{array}$ \\
\hline General Purpose Transfer Payment & $\begin{array}{c}-11.419 \\
(5.84)\end{array}$ & $\begin{array}{r}-15.846 \\
(5.848)\end{array}$ & $\begin{array}{l}-5.201 \\
(5.184)\end{array}$ & $\begin{array}{l}-6.461 \\
(5.04)\end{array}$ \\
\hline Account Balance & $\begin{array}{l}-1.524 \\
(1.657)\end{array}$ & $\begin{array}{c}-1.35 \\
(1.655)\end{array}$ & $\begin{array}{l}-1.963 \\
(1.553)\end{array}$ & $\begin{array}{l}-2.091 \\
(1.518)\end{array}$ \\
\hline
\end{tabular}

This table reports results from the second order spatial model. Both economic neighbors (based on the ranking of GDP per capita) and geographical neighbors refer to cities within the same province. The numbers in parenthesis are standard errors. Time and city fixed effects are controlled for. The number of observations is 1650 . 
GDP ranking, rather than among geographically neighboring cities. ${ }^{19}$ The leveling of the playing field helps increase the intensity of competition among rivals, and thereby induces more effort from all contestants in the tournament. This evidence lends further support for our hypothesis of tournament competition in which the evaluation of regional leaders is based on their relative performance in promoting GDP growth.

\subsubsection{Age-of-Leader Effect}

From the simple model in Section 2, we conjecture that the significance of spatial correlation depends on the age of local leaders. This is consistent with two age-related traits in China's hierarchical political system. First, leaders are faced with a finite career horizon. They are subject to mandatory retirement and the retirement age varies depending on the hierarchical ranks of the leaders. For city leaders, the mandatory retirement age is 60. At the city level, party chiefs normally take office in their forties or fifties. ${ }^{20}$ Therefore the horizon of their careers as a local leader is limited. Figure 1 reports the distribution of the ages of city-level political leaders (party chiefs and mayors) during the period 2000-2005, with each bar representing the average number of leaders that falls in a particular age. The distribution is quite symmetric, with both mean and median ages being around 50 for party chiefs and 49 for mayors. Detailed summary statistics for each year during 2000-2005 are provided in Table 7.

The second trait is that the rate of promotion/termination is highly correlated with age. Here we define termination as either retirement or semi-retirement. It is a common practice in China that leaders are placed in some semi-retirement honorary positions before their formal retirement. ${ }^{21}$ While these positions provide privileges, such as government cars, secretaries, and social status, they do not convey power. Therefore a move into one of these honorary positions will generally be considered as the termination of a political career for a local leader because it is virtually impossible for him/her to be reassigned to positions of power. Given our definition of termination, Figure 2 shows the percentage of city-level party chiefs and mayors being promoted and terminated by age during the period 1997-2005. Clearly, when a party chief is over 53, the chance of getting promoted

\footnotetext{
${ }^{19}$ We also try an alternative definition of a similar GDP ranking based on the GDP level instead of per capita GDP. Results, available from authors upon request, are qualitatively similar.

${ }^{20}$ China maintains a dual-leader system in each level of government, with a party chief and an administrative leader which is the mayor in our study. Party chiefs generally have more power than their administrative partners because party chiefs controls the appointment of personnel.

${ }^{21} \mathrm{~A}$ good example is the leading positions in the local People's Congress or Political and Consultative Conference, an advisory body for the government.
} 
Figure 1: Age Distribution of City Leaders
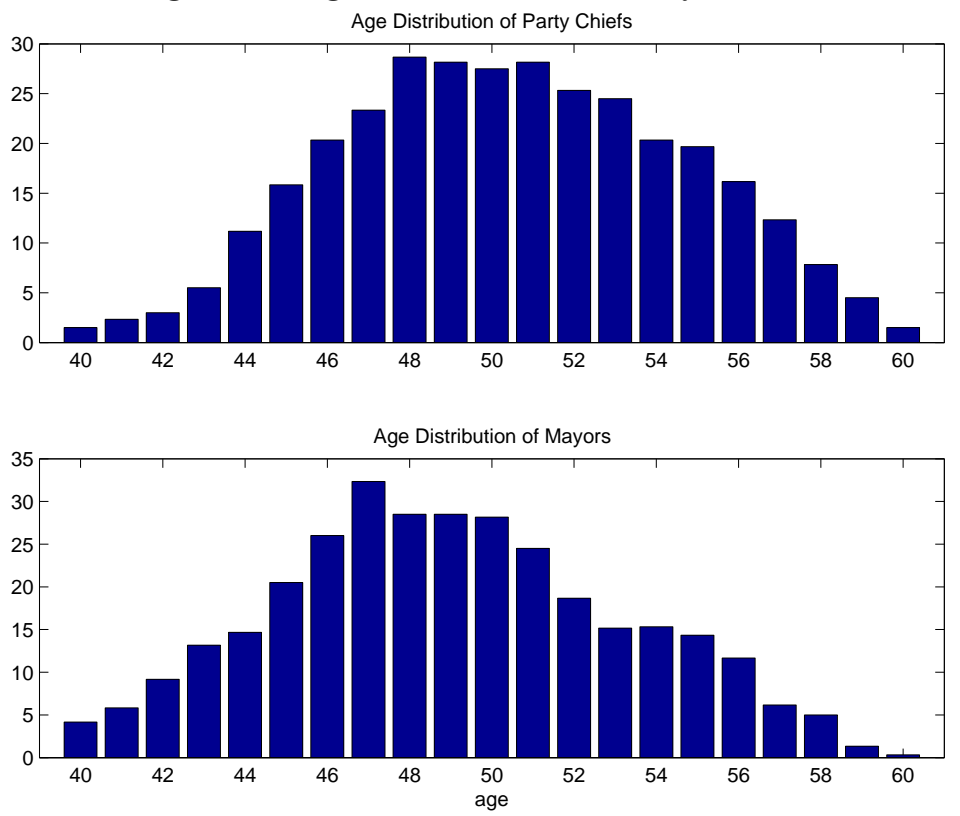

The figure shows the age distribution of party chiefs and mayors of prefectural cities. Each bar represents the average numbers during the period 2000-2005.

plummets and the chance of getting terminated increases sharply. For city mayors, the probability of termination increases rapidly after age 55 .

These age-related traits should affect the competition patterns of local leaders who are forwardlooking. As the model predicts, a leader in his/her last term before termination or retirement should have little incentive to compete with peers, especially with those who are also in their last terms. This should be reflected in a weaker spacial effect among the relatively old leaders.

We empirically study these conjectures, taking an approach similar to Bordignon et al. (2003) that investigates the term limit effect on spatial competition in the Italian municipality tax setting. Specifically, the original regression equation (11) is modified into the following fourth order spatial model (in matrix form)

$$
\begin{aligned}
Y_{n t}= & \gamma Y_{n, t-1}+\lambda_{1} Z_{n} W_{n} Z_{n} Y_{n t}+\lambda_{2} Z_{n} W_{n}\left(I_{n}-Z_{n}\right) Y_{n t}+\lambda_{3}\left(I_{n}-Z_{n}\right) W_{n} Z_{n} Y_{n t} \\
& +\lambda_{4}\left(I_{n}-Z_{n}\right) W_{n}\left(I_{n}-Z_{n}\right) Y_{n t}+X_{n t} \beta+\eta_{n}+\alpha_{t} l_{n}+\epsilon_{n t}
\end{aligned}
$$

where $I_{n}$ is the identity matrix and $Z_{n}$ is a diagonal matrix with $Z_{n}(i, i)=1$ if the leader is 
Figure 2: Promotion and Termination Percentages
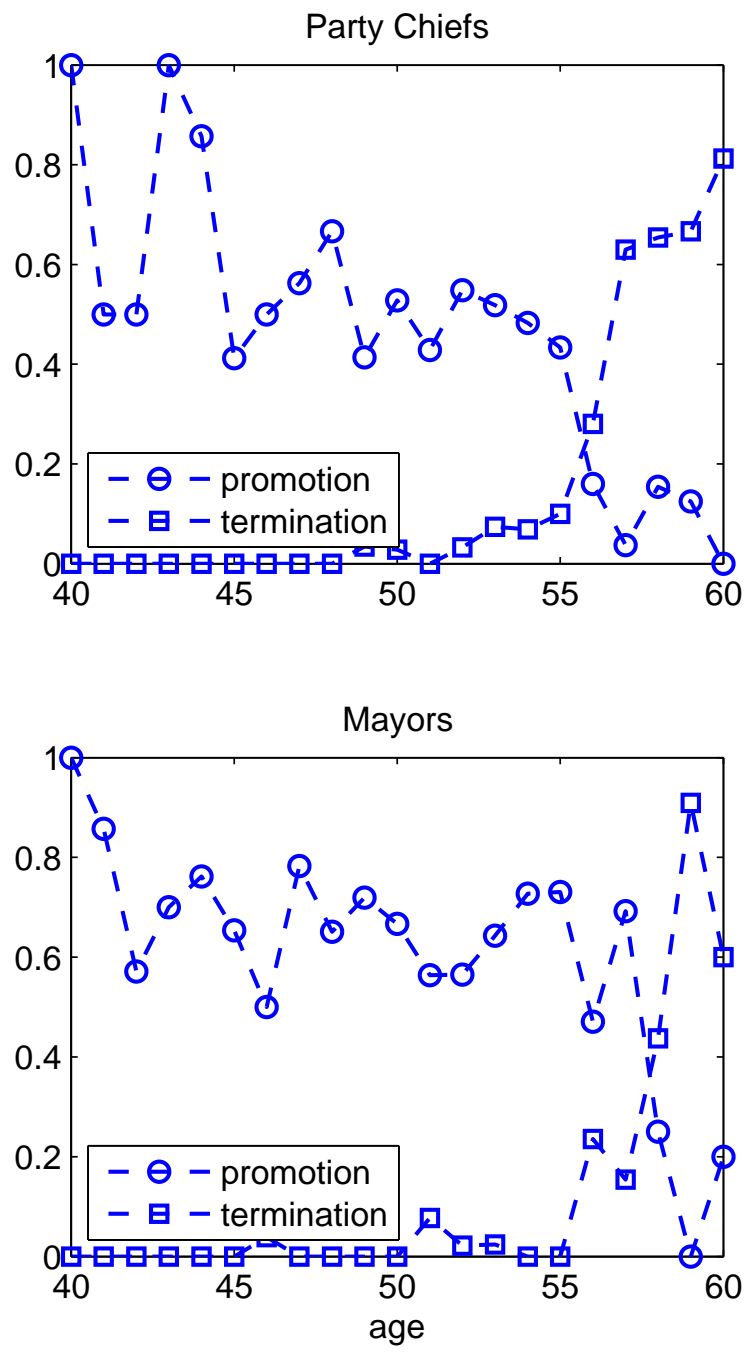

The figure plots the percentages of city party chiefs and mayors being promoted or terminated by age during the period 1997-2005. 
Table 7: Summary Statistics of Ages of Party Chiefs and Mayors

\begin{tabular}{l|cccccc|cccccc}
\hline \hline & \multicolumn{6}{|c|}{ Age of party chiefs } & \multicolumn{5}{c}{ Age of city mayors } \\
\hline & Obs & Mean & Median & SD & Min & Max & Obs & Mean & Median & SD & Min & Max \\
-200 & & & & & & & & & & & & \\
& 1980 & 50.9 & 50.7 & 4.2 & 38.5 & 67.6 & 1980 & 49.2 & 49 & 4.4 & 35.5 & 64.5 \\
2000 & & & & & & & & & & & & \\
2001 & 330 & 51.1 & 51.2 & 4.8 & 38.8 & 67.6 & 330 & 48.9 & 48.5 & 4.7 & 37.5 & 61.5 \\
2002 & 330 & 50.8 & 50.7 & 4.5 & 38.7 & 66.5 & 330 & 48.9 & 48.4 & 4.7 & 35.5 & 62.5 \\
2003 & 330 & 50.4 & 50.6 & 4.3 & 39.5 & 67.5 & 330 & 49.2 & 48.8 & 4.4 & 36.5 & 63.5 \\
2004 & 330 & 50.9 & 50.7 & 3.9 & 40.1 & 61.3 & 330 & 49 & 49 & 4.2 & 37.5 & 64.5 \\
2005 & 330 & 51.2 & 51.1 & 3.8 & 39.5 & 59.4 & 330 & 49.4 & 49.4 & 4.2 & 38.5 & 59.9 \\
\hline \hline
\end{tabular}

This table shows summary statistics of the ages of government leaders in 330 prefectural level cities in China. SD stands for standard deviation. Source: Author's collection.

older than a cutoff age. Essentially, based on the cutoff age, the original weights matrix $W_{n}$ is decomposed into four components, where $Z_{n} W_{n} Z_{n}$ measures how old leaders respond to their old neighbors, $Z_{n} W_{n}\left(I_{n}-Z_{n}\right)$ measures how older leaders respond to their younger neighbors, and $\left(I_{n}-Z_{n}\right) W_{n} Z_{n}$ and $\left(I_{n}-Z_{n}\right) W_{n}\left(I_{n}-Z_{n}\right)$ are defined similarly. By doing so, for a given dependent variable in LHS (either for a younger or an older leader), only the neighbors with a similar age are averaged as the RHS. Thus, we have in total four parameters of $\lambda_{1}, \lambda_{2}, \lambda_{3}$ and $\lambda_{4} \cdot{ }^{22}$ By comparing the size of the coefficients related to the two weights matrices that we are interested in, $\lambda_{1}$ and $\lambda_{2}$ respectively, we gain understanding regarding whether and how old leaders have different spatial responsiveness to their young and old neighbors.

We consider various cutoff ages, with results reported in Table 8. The upper block of the table shows results for party chiefs and the lower block show results for city mayors. The row labeled "Old vs. Young" shows the spatial correlation between old leaders (age greater than or equal to the cutoff) and young leaders (age less than the cutoff). "Old vs. Old" row shows spatial correlation among old leaders.

The pattern of "Old vs. Old" spatial correlation is clear. The correlation increases with cutoff age until it reaches a peak at about age 53 for party chiefs and 54 for mayors. When the cutoff age is 56-57, the spatial correlation is much lower and becomes insignificant. This pattern is highly

\footnotetext{
${ }^{22}$ Bordignon et al. (2003) decompose $W_{n}$ into $Z_{n} W_{n}$ and $\left(I_{n}-Z_{n}\right) W_{n}$, which measure how the old/young leaders respond to their neighbors, regardless of the nature of his/her neighbors. In their regression, for a given dependent variable in LHS, neighbors with leaders of different age levels are averaged as RHS. Thus, they have two spatial effects of $\lambda_{1}$ and $\lambda_{2}$.
} 
consistent with the above two age-related traits. At age 53 or 54, many leaders are faced with their final chance of getting promoted, hence are motivated to compete aggressively with peers, especially with those of similar age. As the cutoff age increases, the "old" leaders approach their last terms before termination or formal retirement, and they have little incentive to compete, because the probability of promotion is close to zero regardless.

Comparing the above pattern with Figure 2, the picture becomes clearer. Starting from age 53-54, the percentage of leaders getting promoted falls steadily, while the percentage of leaders getting terminated rises rapidly. This is exactly the cutoff age at which the spatial effect starts to diminish. When the leaders get older, the probability of promotion falls below the probability of termination, and the spatial effect among old leaders comes close to zero.

The pattern of "Old vs. Young" spatial correlation is less clear, partly because the definition of "young leader" is too broad - anyone younger than the cutoff age is considered as a young leader. For example, when the cutoff age is 55, any leader younger than 55 is defined as a young leader. Nevertheless, it is evident that when the cutoff age is 55 or older, old leaders become less and less responsive to the investment of young leaders. Based on our theory, this is again due to the fact that the probability of promotion is extremely low when an leader is older than 55 .

An alternative approach to investigate the age-of-leader effect is to include the interaction of age dummies and neighbors' investment in the regression. This approach assumes that a city leader does not care about the ages of competitors, which is a restrictive assumption. As we discussed in the model, the competition among older leaders should be weaker. On the other hand, the approach of equation (13) allows the distinction of old-old competition and old-young competition, and therefore should be preferred.

\section{$5 \quad$ Spatial Effect and Strategic Interaction: Further Evidence}

We have documented three salient patterns of spatial correlation regarding city level total investment, and each is well explained by the theory of strategic interaction among local leaders engaging in tournament competition. This section provides further evidence that the documented spatial effect is driven by tournament competition. We first discuss two alternative explanations of a spillover effect, and then examine the spatial effect of education expenditure across cities. 
Table 8: Spatial Correlation: Age-of-Leader Effect

\begin{tabular}{|c|c|c|c|c|c|c|c|}
\hline Cutoff Age & 51 & 52 & 53 & 54 & 55 & 56 & 57 \\
\hline \multicolumn{8}{|c|}{ Party chiefs } \\
\hline Old vs. Old & $\begin{array}{c}0.272 \\
(0.031)\end{array}$ & $\begin{array}{c}0.282 \\
(0.032)\end{array}$ & $\begin{array}{c}0.290 \\
(0.040)\end{array}$ & $\begin{array}{c}0.266 \\
(0.046)\end{array}$ & $\begin{array}{c}0.228 \\
(0.051)\end{array}$ & $\begin{array}{c}0.156 \\
(0.059)\end{array}$ & $\begin{array}{c}0.098 \\
(0.115)\end{array}$ \\
\hline Old vs. Young & $\begin{array}{c}0.155 \\
(0.048)\end{array}$ & $\begin{array}{c}0.164 \\
(0.045)\end{array}$ & $\begin{array}{c}0.232 \\
(0.041)\end{array}$ & $\begin{array}{c}0.185 \\
(0.049)\end{array}$ & $\begin{array}{c}0.280 \\
(0.054)\end{array}$ & $\begin{array}{c}0.276 \\
(0.072)\end{array}$ & $\begin{array}{c}0.249 \\
(0.081)\end{array}$ \\
\hline \multicolumn{8}{|c|}{ Mayors } \\
\hline Old vs. Old & $\begin{array}{r}0.227 \\
(0.040)\end{array}$ & $\begin{array}{c}0.294 \\
(0.044)\end{array}$ & $\begin{array}{c}0.257 \\
(0.051)\end{array}$ & $\begin{array}{c}0.376 \\
(0.061)\end{array}$ & $\begin{array}{c}0.137 \\
(0.091)\end{array}$ & $\begin{array}{l}-0.012 \\
(0.132)\end{array}$ & $\begin{array}{c}0.030 \\
(0.234)\end{array}$ \\
\hline Old vs. Young & $\begin{array}{r}0.199 \\
(0.037)\end{array}$ & $\begin{array}{c}0.240 \\
(0.039)\end{array}$ & $\begin{array}{c}0.248 \\
(0.039)\end{array}$ & $\begin{array}{c}0.186 \\
(0.042)\end{array}$ & $\begin{array}{c}0.263 \\
(0.041)\end{array}$ & $\begin{array}{c}0.151 \\
(0.056)\end{array}$ & $\begin{array}{c}0.129 \\
(0.083)\end{array}$ \\
\hline
\end{tabular}

This table reports the spatial effect of old leaders competing with neighboring young/old leaders. Old leaders are those whose age is above the cutoff age. The numbers in parenthesis are standard errors. Time and city fixed effects are controlled for. The number of observation is 1650 .

\subsection{Spillover Effect}

An obvious alternative interpretation for the spatial correlation across cities is an economic spillover effect. ${ }^{23}$ A city's increased investment is likely to make investment in neighboring cities more profitable in the short-run. ${ }^{24}$ Thus, for instance, construction of a freeway which connects a series of cities will be captured by our empirical model as a spatial effect.

We argue that the pure economic spillover is unlikely to drive our observed spatial effect for several reasons. First, it is unlikely that the strength of economic spillover depends on the age of local leaders. In particular, our results show that the spatial effect declines sharply when the age of a city leader hits 56. This discontinuity effect is only consistent with the age-based patterns of promotion and termination probabilities among city leaders, but not consistent with the economic spillover effect.

Second, economic spillover should be more likely to appear among geographically proximate cities since some key channels of spillover (e.g. the flow of goods and people) rely on distance. This prediction seems to be at odds with the border effect of spatial correlation. In addition, the GDP ranking effect within the provinces is more consistent with the tournament competition hypothesis,

\footnotetext{
${ }^{23}$ A spillover effect could be caused by industrial clustering as studied by Long and Zhang (2011).

${ }^{24}$ Brun et al. (2002) find little evidence of spillover effect for the growth of one city on another in the long run.
} 
rather than the hypothesis of the spillover effect.

People may still argue that the border effect of spatial correlation could be consistent with the spillover story. Spillover could be confined within a province simply because many province borders in China are comprised of mountains which may impede cross-province spillover.

To test this possibility and rule out the spillover story, we run spatial regression with redefined across-province geographical neighbors. Specifically, two cities from different provinces are neighbors if they are (i) geographically proximate, and (ii) not separated by mountains. The corresponding weights matrix is $\widetilde{G}^{\text {across }}$ in Table 1 . Recall that $G^{\text {across }}$ does not impose condition (ii), thus $\widetilde{G}^{\text {across }}$ is more stringent in selecting neighbors. ${ }^{25}$

If the spillover hypothesis holds, we should expect increased spatial correlation for cities across province borders by using $\widetilde{G}^{\text {across }}$. However, we find no evidence for this. The spatial effect is still confined within a province and does not go beyond provincial borders, as shown in Table 9. Both first order and high order models yield regression coefficients that are nearly the same as those in the baseline case where $G^{\text {across }}$ is used.

\subsection{Tax Competition}

Short-run investment boosts not just economic growth but also tax revenues. The spatial effect for total investment might also be driven by tax competition among city governments. ${ }^{26}$ Due to fiscal decentralization since the early 1980s in China, local governments have incentives to generate more tax revenues by attracting mobile capital (Montinola et al., 1995; Qian and Weingast, 1997; Roland and Qian, 1998; Jin et al., 2005). One of the key policy instruments is tax rates. ${ }^{27}$ Some studies have found evidence for tax competition across China's regions (Yao and Zhang, 2008; Chen et al., 2014).

Interjurisdictional tax competition may coincide with tournament competition if the ultimate goal of local leaders to attract mobile capital and collect taxes is to promote GDP growth and increase promotion chances relative to their political rivals. In this case, tax competition derives from tournament incentives, and the evidence for the former is consistent with our hypothesis about tournament competition. But if the tax competition theory assumes that local leaders only care about tax revenues per se and they have no career concerns, as most studies do, the implications are

\footnotetext{
${ }^{25}$ By this definition, each city has 2.11 neighbors on average from other provinces. Before removing neighbors with mountain barriers, the number of neighbors is 2.18 on average from other provinces.

${ }^{26}$ See Wilson (1999) for a comprehensive review of theories of tax competition.

${ }^{27}$ While in China local tax rates are set up by the central government, local governments have discretion in tax enforcement, which leads to differences in the effective tax rates across regions.
} 
Table 9: Robustness Check for Border Effect

\begin{tabular}{|c|c|c|}
\hline \multicolumn{3}{|c|}{ Dependent Variable: Investment } \\
\hline & $\widetilde{G}^{\text {cross }}$ & $\begin{array}{c}G^{\text {within }} \\
\text { and } \widetilde{G}^{\text {cross }}\end{array}$ \\
\hline \multirow[t]{2}{*}{ Investment of Neighbors (within) } & - & 0.379 \\
\hline & - & $(0.037)$ \\
\hline \multirow[t]{2}{*}{ Investment of Neighbors (cross) } & 0.000 & -0.026 \\
\hline & $(0.026)$ & $(0.022)$ \\
\hline \multicolumn{3}{|l|}{ City Level Controls } \\
\hline \multirow[t]{2}{*}{ Lagged Investment } & 0.288 & 0.26 \\
\hline & $(0.136)$ & $(0.081)$ \\
\hline \multirow[t]{2}{*}{ Account Balance } & 7.475 & 9.809 \\
\hline & $(4.307)$ & $(3.895)$ \\
\hline \multirow[t]{2}{*}{ Fiscal Revenue } & 47.711 & 44.842 \\
\hline & $(7.45)$ & $(4.41)$ \\
\hline \multirow{2}{*}{ Fiscal Population } & 24.547 & 7.439 \\
\hline & $(23.018)$ & $(20.807)$ \\
\hline \multirow[t]{2}{*}{ Manufacturing ratio } & 128.975 & 41.547 \\
\hline & $(38.732)$ & $(36.088)$ \\
\hline \multirow[t]{2}{*}{ GDP per capita } & -132.1 & -90.288 \\
\hline & $(35.545)$ & $(29.747)$ \\
\hline \multirow[t]{2}{*}{ Transfer Payment } & 39.734 & 35.566 \\
\hline & $(6.505)$ & $(5.361)$ \\
\hline \multicolumn{3}{|l|}{ Provincial Government Controls } \\
\hline \multirow[t]{2}{*}{ Fiscal Revenue } & 2.448 & 0.811 \\
\hline & $(1.608)$ & $(1.458)$ \\
\hline \multirow[t]{2}{*}{ Fiscal Expenditure } & -1.024 & -1.113 \\
\hline & $(1.091)$ & $(0.98)$ \\
\hline \multirow[t]{2}{*}{ Public Capital Investment } & -13.842 & -10.967 \\
\hline & $(3.333)$ & $(3.006)$ \\
\hline \multirow[t]{2}{*}{ Transfer Payment } & 7.075 & 3.713 \\
\hline & $(1.789)$ & $(1.644)$ \\
\hline \multirow[t]{2}{*}{ General Purpose Transfer Payment } & -22.854 & -2.489 \\
\hline & $(6.505)$ & $(5.407)$ \\
\hline \multirow[t]{2}{*}{ Account Balance } & 0.033 & -1.928 \\
\hline & $(1.807)$ & $(1.604)$ \\
\hline
\end{tabular}

This table reports results based on geographical weights matrices, with cities separated by mountain not treated as neighbors. The numbers in parenthesis are standard errors. Time and city fixed effects are controlled for. The number of observations is 1650. 
different from our tournament competition hypothesis. According to this theory, tax competition should occur among regions across which tax bases are mobile. While capital and labor of stateowned enterprises can be considered immobile across provinces in China, production factors of private or foreign enterprises are clearly mobile. For example, Liu and Jorge Martinez-Vazquez (2014) finds strong evidence of tax competition among provincial governments in China. Given this cross-province mobility, the tax competition hypothesis should generate significant spatial effect for geographically proximate cities from difference provinces. However we find that spatial effect of investment is strictly confined within a province. In addition, the age-of-leader effect, especially the discontinuity effect around age 56, can hardly be explained by the tax competition hypothesis which assumes no role for career concerns.

\subsection{Spatial Effect of Education Expenditure}

Tournament competition depends critically on the link between a competitor's action and his/her career advancement. In the simple model laid out in Section 2, when the leader's utility $u($.$) is not an increasing function, leaders do not react strategically to the action of peers.$ Therefore an alternative way to test the tournament competition theory is to find an economic variable that does not increase the odds of promotion. Our theory predicts zero spatial correlation for such a variable.

We choose education expenditure to test this hypothesis. The reasons for choosing education expenditure are twofold. First, education expenditure helps little in boosting short-run economic growth, although it promotes long-run growth. Given that a local leader holds his/her position for 3-5 years on average, education expenditure should not be correlated with promotion odds. Second, local governments have a great deal of freedom to increase education expenditures. In China, local governments have contributed to over 95 percent of total government expenditures on education.

Table 10 reports the results. Overall the spatial effect is small both economically and statistically. Results in the left columns are based on the first order spatial model. For the neighbors from the same province, education expenditure does not exhibit much spatial correlation compared with total investment. For example, the within province spatial effect is 0.119 and 0.011 for geographical and economic neighbors respectively, but the corresponding figures for total investment are 0.353 and 0.119 when we study total investment. For the neighbors from neighboring provinces, the spatial effect is both statistically and economically negligible. Turning to the more general high order spatial model, the spatial effect of education expenditure is even smaller, both economically 
Table 10: Spatial Correlation of Education Expenditure

\begin{tabular}{|c|c|c|c|c|c|c|}
\hline \multicolumn{7}{|c|}{ Dependent Variable: Education Expenditure } \\
\hline & $G^{\text {within }}$ & $E^{\text {within }}$ & $G^{\text {cross }}$ & $E^{\text {cross }}$ & $\begin{array}{c}G^{\text {within }} \\
\text { and } G^{\text {cross }}\end{array}$ & $\begin{array}{c}E^{\text {within }} \\
\text { and } E^{\text {cross }}\end{array}$ \\
\hline Expenditure of Neighbors (within) & $\begin{array}{c}0.119 \\
(0.053)\end{array}$ & $\begin{array}{c}0.011 \\
(0.024)\end{array}$ & - & - & $\begin{array}{l}0.131 \\
(0.05)\end{array}$ & $\begin{array}{c}0.02 \\
(0.023)\end{array}$ \\
\hline Expenditure of Neighbors (cross) & - & - & $\begin{array}{l}-0.003 \\
(0.029)\end{array}$ & $\begin{array}{l}-0.022 \\
(0.029)\end{array}$ & $\begin{array}{l}-0.016 \\
(0.028)\end{array}$ & $\begin{array}{l}-0.024 \\
(0.026)\end{array}$ \\
\hline \multicolumn{7}{|l|}{ City Level Controls } \\
\hline Lagged Expenditure & $\begin{array}{c}1.402 \\
(0.095)\end{array}$ & $\begin{array}{c}1.159 \\
(0.081)\end{array}$ & $\begin{array}{l}1.343 \\
(0.09)\end{array}$ & $\begin{array}{c}1.236 \\
(0.086)\end{array}$ & $\begin{array}{l}1.305 \\
(0.079)\end{array}$ & $\begin{array}{c}1.011 \\
(0.062)\end{array}$ \\
\hline Account Balance & $\begin{array}{l}-2.721 \\
(0.326)\end{array}$ & $\begin{array}{c}-2.22 \\
(0.286)\end{array}$ & $\begin{array}{l}-2.609 \\
(0.314)\end{array}$ & $\begin{array}{l}-2.387 \\
(0.298)\end{array}$ & $\begin{array}{l}-2.518 \\
(0.296)\end{array}$ & $\begin{array}{l}-1.906 \\
(0.252)\end{array}$ \\
\hline Fiscal Revenue & $\begin{array}{l}0.885 \\
(0.21)\end{array}$ & $\begin{array}{l}1.361 \\
(0.18)\end{array}$ & $\begin{array}{c}1.039 \\
(0.198)\end{array}$ & $\begin{array}{c}1.258 \\
(0.193)\end{array}$ & $\begin{array}{l}1.055 \\
(0.182)\end{array}$ & $\begin{array}{c}1.653 \\
(0.152)\end{array}$ \\
\hline Fiscal Population & $\begin{array}{l}-1.795 \\
(1.425)\end{array}$ & $\begin{array}{c}-0.844 \\
(1.263)\end{array}$ & $\begin{array}{l}-1.383 \\
(1.381)\end{array}$ & $\begin{array}{c}-1.047 \\
(1.31)\end{array}$ & $\begin{array}{l}-1.496 \\
(1.348)\end{array}$ & $\begin{array}{l}-0.396 \\
(1.176)\end{array}$ \\
\hline Manufacturing ratio & $\begin{array}{c}3.529 \\
(2.419)\end{array}$ & $\begin{array}{c}3.049 \\
(2.135)\end{array}$ & $\begin{array}{c}3.967 \\
(2.333)\end{array}$ & $\begin{array}{c}3.421 \\
(2.215)\end{array}$ & $\begin{array}{c}3 \\
(2.293)\end{array}$ & $\begin{array}{c}2.324 \\
(1.989)\end{array}$ \\
\hline GDP per capita & $\begin{array}{c}4.976 \\
(1.937)\end{array}$ & $\begin{array}{c}4.692 \\
(1.706)\end{array}$ & $\begin{array}{c}4.411 \\
(1.865)\end{array}$ & $\begin{array}{c}4.679 \\
(1.775)\end{array}$ & $\begin{array}{c}5.147 \\
(1.842)\end{array}$ & $\begin{array}{c}5.024 \\
(1.603)\end{array}$ \\
\hline Transfer Payment & $\begin{array}{c}-1.16 \\
(0.383)\end{array}$ & $\begin{array}{l}-0.643 \\
(0.336)\end{array}$ & $\begin{array}{l}-0.983 \\
(0.371)\end{array}$ & $\begin{array}{l}-0.791 \\
(0.35)\end{array}$ & $\begin{array}{l}-0.964 \\
(0.356)\end{array}$ & $\begin{array}{l}-0.371 \\
(0.304)\end{array}$ \\
\hline \multicolumn{7}{|l|}{ Provincial Government Controls } \\
\hline Fiscal Revenue & $\begin{array}{c}0.000 \\
(0.096)\end{array}$ & $\begin{array}{c}0.034 \\
(0.085)\end{array}$ & $\begin{array}{c}0.03 \\
(0.093)\end{array}$ & $\begin{array}{c}0.037 \\
(0.088)\end{array}$ & $\begin{array}{c}0.008 \\
(0.092)\end{array}$ & $\begin{array}{l}0.042 \\
(0.08)\end{array}$ \\
\hline Fiscal Expenditure & $\begin{array}{l}-0.103 \\
(0.065)\end{array}$ & $\begin{array}{c}-0.083 \\
(0.058)\end{array}$ & $\begin{array}{l}-0.093 \\
(0.064)\end{array}$ & $\begin{array}{l}-0.089 \\
(0.06)\end{array}$ & $\begin{array}{l}-0.104 \\
(0.063)\end{array}$ & $\begin{array}{l}-0.079 \\
(0.054)\end{array}$ \\
\hline Public Capital Investment & $\begin{array}{c}0.298 \\
(0.208)\end{array}$ & $\begin{array}{c}0.211 \\
(0.185)\end{array}$ & $\begin{array}{c}0.296 \\
(0.202)\end{array}$ & $\begin{array}{c}0.243 \\
(0.192)\end{array}$ & $\begin{array}{c}0.252 \\
(0.197)\end{array}$ & $\begin{array}{c}0.137 \\
(0.173)\end{array}$ \\
\hline Transfer Payment & $\begin{array}{l}-0.065 \\
(0.108)\end{array}$ & $\begin{array}{l}-0.074 \\
(0.096)\end{array}$ & $\begin{array}{l}-0.074 \\
(0.105)\end{array}$ & $\begin{array}{l}-0.07 \\
(0.1)\end{array}$ & $\begin{array}{l}-0.062 \\
(0.103)\end{array}$ & $\begin{array}{l}-0.068 \\
(0.091)\end{array}$ \\
\hline General Purpose Transfer Payment & $\begin{array}{c}0.091 \\
(0.349)\end{array}$ & $\begin{array}{l}-0.087 \\
(0.302)\end{array}$ & $\begin{array}{l}-0.102 \\
(0.329)\end{array}$ & $\begin{array}{l}-0.133 \\
(0.316)\end{array}$ & $\begin{array}{c}0.114 \\
(0.332)\end{array}$ & $\begin{array}{l}-0.114 \\
(0.286)\end{array}$ \\
\hline Account Balance & $\begin{array}{l}-0.014 \\
(0.114)\end{array}$ & $\begin{array}{c}0.107 \\
(0.096)\end{array}$ & $\begin{array}{c}0.076 \\
(0.105)\end{array}$ & $\begin{array}{c}0.102 \\
(0.1)\end{array}$ & $\begin{array}{l}-0.003 \\
(0.107)\end{array}$ & $\begin{array}{l}0.139 \\
(0.09)\end{array}$ \\
\hline
\end{tabular}

This table reports spatial effect of education expenditure based on various weights matrices. The numbers in parenthesis are standard errors. Time and city fixed effects are controlled for. The number of observations is 1650 . 
and statistically, as shown in the right columns of Table 10. Overall, as a falsification test, these results are supportive of the tournament competition theory.

One concern about the lack of spatial effects in education expenditure is that local leaders may not have much discretion in altering education expenditure because it is mandated by higher-level authorities to a large extent. For example, a large fraction of education expenditure derives from wage bills, and base wage levels should be quite stable over time and across regions, although bonus and overtime compensation can vary substantially. To ease this concern, we compare the coefficient of variation $(\mathrm{CV})$ of total investment and education expenditure. The CV of education turns out to be 0.87 which is about $60 \%$ of the $\mathrm{CV}$ of total investment. Hence the education expenditure exhibits a reasonable degree of variation. As a further check, we regress education expenditure on city dummies and time dummies to obtain the residual, and define a residual CV as the standard deviation of the residual divided by the mean of education expenditure. This residual CV is 0.24. Applying the same procedure to total investment, the residual CV for total investment is 0.58. Considering the fact that investment is a highly volatile variable and that education expenditure can be as 40-60 percent volatile as investment, we argue that city-level education expenditures exhibit enough variation to support the assertion that local leaders do have considerable discretion in allocating education expenditures.

\section{Conclusion}

We have presented strong evidence that local leaders in China engage in tournament competition and strategically boost total investment. The institutional foundation of such competition is the unique combination of political centralization and economic regional decentralization in China.

After analyzing a simple model of local government leaders' optimization behavior, we employ spatial econometrics models to carry out the empirical analysis. We document significant spatial correlation of total investment among cities within the same province, which is consistent with the tournament competition theory. Three patterns are prominent. First, spatial correlation is strictly confined within a province. Second, cities with similar ranking in GDP per capita exhibit the strongest spatial correlation. Third, the degree of spatial correlation depends on the age of leaders. The correlation is significantly weaker among city leaders who are near the mandatory termination age.

Additional evidence is provided to show that the documented spatial effect is driven by tournament competition, rather than by economic spillover or pure tax competition. Furthermore, no 
spatial effect is found for city level education expenditures, which is also consistent with the theory of tournament competition.

Based on this multi-faceted empirical evidence, we argue that tournament competition is prevalent among leaders of rival cities in China, and leaders behave strategically in the competition. Our finding has important policy implications. In pursuit of sustained economic growth, scholars and policy makers in China have been advocating changes to the current promotion scheme to include additional criteria such as environmental protection. Results in this paper imply that local leaders may significantly change their behavior in response to such changes in personnel evaluation. Another implication is that the high share of aggregate investment in GDP might be partly explained by the tournament competition. It will be worthwhile to study to what extent the current promotion scheme causes over-investment and how this affects social welfare. We leave these interesting questions to the future research.

\section{Appendix A: Variable Descriptions}

Total Investment is defined as the sum of residential and non-residential investment made by various types of enterprises and the government. Education Expenditure is defined as expenditures by a local government on various public schools and other education-related agencies. It includes (i) salary, subsidy, bonus, insurance and additional benefits of teachers and other related personnel; (ii) expenses on utility, stationery, equipment, furniture and other durables; and (iii) expenditures on education-related construction and renovation. Fiscal Account Balance is the accumulated fiscal balance, i.e., the total fiscal surplus of the previous years. Fiscal Population measures the population whose compensation is paid out of the government budget, including people working in administration, public schools, state-owned-enterprises, collective-owned enterprises and other government units. It also includes compensation of retired staff. Manufacturing ratio is defined as the ratio of secondary industry value added divided by the city GDP. Fiscal Revenue is the total fiscal revenue of a city, including the budgetary revenue and extra-budgetary revenue. Transfer Payment encompasses total transfer payments from the higher-level government, including the provincial government and central government.

At the province level, Fiscal Revenue, Fiscal Expenditure and Account Balance are similarly defined. Public Capital Investment is the public capital formation investment funded by the 
provincial government. Transfer Payment is the redistribution of fiscal income from the central government, which includes general purpose payment and special purpose payments. The General Purpose Transfer Payment can be used with discretion by the provincial government, but the special purpose payment has to be used for the purpose specified by the central government.

\section{Appendix B: Econometrics Issues}

To estimate (11) and (12), we need to consider the endogeneity issue introduced by the spatial lag term. Also, as discussed in the dynamic panel data literature, we need to consider the incidental parameter problem, also known as the Nickell bias problem, caused by the many-city effects (as the time period $T=6$ is short, we can treat the time effects as dummy variables and do not need to worry about the incidental parameter problem from the time dimension).

For the incidental parameter problem, we use the forward orthogonal difference (FOD) transformation to eliminate the city effects. For FOD, the transformed dependent variable $y_{i t}^{*}=$ $\left(\frac{T-t}{T-t+1}\right)^{\frac{1}{2}}\left[y_{i t}-\frac{1}{T-t} \sum_{h=t+1}^{T} y_{i h}\right]$ and the lag term $y_{i, t-1}^{(*,-1)}=\left(\frac{T-t}{T-t+1}\right)^{\frac{1}{2}}\left[y_{i, t-1}-\frac{1}{T-t} \sum_{h=t}^{T-1} y_{i h}\right]$ depend on current and future variables, but not on the past ones. Essentially, the FOD is a deviation from the future time average, which can eliminate the time invariant city effects. Similarly, we can apply the FOD in the cross sectional dimension to eliminate the time effects, which will yield a new spatial weights matrix $W_{n}^{*}$. Thus, by applying FOD to both the time and cross sectional dimensions, the estimation equation (11) becomes

$$
y_{i t}^{*}=\gamma y_{i, t-1}^{(*,-1)}+\lambda \sum_{j \neq i}^{n} w_{i j}^{*} y_{j t}^{*}+x_{i t}^{* \prime} \beta+z_{p t}^{* \prime} \delta+\epsilon_{i t}^{*},
$$

where elements of $\epsilon_{i t}^{*}$ are still homogenous and uncorrelated if the original $\epsilon_{i t}$ is i.i.d. We note that the dynamic lag term $y_{i, t-1}^{(*,-1)}$ is correlated with $\epsilon_{i t}^{*}$. For this reason, IVs are needed for $y_{i, t-1}^{(*,-1)}$. In dynamic panel data literature (Anderson and Hsiao, 1981; Arellano and Bover 1995; Alvarez and Arellano, 2003; etc.), lagged values of dependent variables can be used as IVs, along with all periods of exogenous variables.

The endogeneity problem of spatial effect comes from the fact that the spatial lag term $\sum_{j \neq i}^{n} w_{i j}^{*} y_{j t}^{*}$ is correlated with $\epsilon_{i t}^{*}$ because the dependent variable $y_{i t}^{*}$ is correlated with $\epsilon_{i t}^{*}$. In spatial econometrics literature, the spatial lags of independent variables can be used as IVs (see Kelejian and Prucha, 1998) such as $\sum_{j \neq i}^{n} w_{i j}^{*} x_{j t}^{*}$. For the spatial dynamic panel data, the spatial lags of lag terms can also be used as IVs such as $\sum_{j \neq i}^{n} w_{i j}^{*} y_{j, t-1}^{(*,-1)}$. 
In the matrix form, (14) can be written as

$$
Y_{n t}^{*}=\gamma Y_{n, t-1}^{(*,-1)}+\lambda W_{n}^{*} Y_{n t}^{*}+X_{n t}^{*} \beta+Z_{n t}^{*} \delta+\epsilon_{n t}^{*},
$$

where $Y_{n t}^{*}=\left(y_{1 t}^{*}, y_{2 t}^{*}, \ldots, y_{n t}^{*}\right)^{\prime}$ is $n \times 1$ vector of dependent variables and other variables are defined similarly. The IV matrix for (15) is $\left[\begin{array}{c}Y_{n, t-1}, \cdots, Y_{n, t-k}, X_{n 1}^{*}, \cdots, X_{n T}^{*}, Z_{n 1}^{*}, \ldots, Z_{n T}^{*}, \\ W_{n} Y_{n, t-1}, \cdots, W_{n} Y_{n, t-k}, W_{n} X_{n 1}^{*}, \cdots, W_{n} X_{n T}^{*} \\ \vdots \\ W_{n}^{p} Y_{n, t-1}, \cdots, W_{n}^{p} Y_{n, t-k}, W_{n}^{p} X_{n 1}^{*}, \cdots, W_{n}^{p} X_{n T}^{*}\end{array}\right]$, where $k$ denotes how many time lags to instrument the endogenous lagged value, and $p$ denotes how many spatial lags to instrument the endogenous spatial lag. We note that for province level variable $Z_{n t}^{*}$, they are the same for cities in the same province, so that the spatial lag $W_{n}^{*} Z_{n t}^{*}$ is the same as $Z_{n t}^{*}$.

There is a literature on IV and GMM estimation with many moment conditions, for example, in nonlinear simultaneous equations models or conditional moments restrictions models. Many moments decrease the variances of the IV or GMM estimates, but increase their biases. For the dynamic panel data literature, many IVs comes from the all the lagged value when $T$ is large. For the spatial econometrics literature, many IVs comes from infinite spatial expansion of regressors. Thus, there is an optimal choice of number of IVs, which is equivalent to choose $k$ and $p$ to minimize the mean squared error (MSE). As investigated in Lee and Yu (2014), the MSE of estimates are usually minimized at a small value of $k$ and $p$. We choose $k=1$ and $p=2$ in our empirical estimation, and other specifications yield similar results.

\section{References}

Agostini, Claudio A., Philip Brown and Xiaobo Zhang, 2010. Neighbor effects in the provision of public goods in a young democracy: Evidence from China. IFPRI discussion papers 1027, International Food Policy Research Institute.

Agrawal, David R., 2015. The Tax Gradient: Spatial Aspects of Fiscal Competition. American Economic Journal: Economic Policy 7, 1-29.

Alesina, Alberto F., Ugo Troiano and Traviss Cassidy, 2015. Old and young politicians. Working Paper 2097\%. 
Alvarez, Javier and Manuel Arellano, 2003. The time series and cross-section asymptotics of dynamic panel data estimators. Econometrica 71, 1121-1159.

Anderson, Theodore W. and Cheng Hsiao, 1981. Estimation of dynamic models with error components. Journal of the American Statistical Association 76, 598-606.

Arellano, Manuel and Olympia Bover, 1995. Another look at the instrumental-variable estimation of error-components models. Journal of Econometrics 68, 29-51.

Baicker, Katherine, 2005. The spillover effects of state spending. Journal of Public Economics 89, 529-544.

Bardhan, Pranab and Dilip Mookherjee, 2006. The rise of local governments: an overview. In Decentralization and Local Governance in Developing Countries: A Comparative Perspective. MIT Press.

Besley, Timothy and Anne Case, 1995. Incumbent behavior: vote-seeking, tax-setting, and Yardstick competition. American Economic Review 85, 25-45.

Bordignon, Massimo, Floriana Cerniglia, and Federico Revelli, 2003. In search of yardstick competition: a spatial analysis of Italian municipality tax setting. Journal of Urban Economics 54, 199-217.

Brueckner, Jan K., 1998. Testing for strategic interaction among local governments: the case of growth controls. Journal of Urban Economics 44, 438-467.

Brueckner, Jan K., 2003. Strategic interaction among governments: an overview of theoretical studies. International regional Science Review 26, 175-188.

Brun, Jean-François, Jean-Louis Combes, and Mary-Françoise Renard, 2002. Are there spillover effects between coastal and non-coastal cities in China? China Economic Review 13, 161-169.

Caldeira, Emilie, 2012. Yardstick competition in a federation: Theory and evidence from China. China Economic Review 23, 878-897.

Case, Anne, Harvey Rosen, and James R. Hines Jr., 1993. Budget spillovers and fiscal policy interdependence: evidence from the United States. Journal of Public Economics 52, 285-307.

Cassette, Aurlie, Edoardo Di Porto and Dirk Foremny 2012. Strategic fiscal interaction across borders: Evidence from French and German local governments along the Rhine Valley. Journal of Urban Economics 72, 17-30.

Chen, Yu, Zhigang Li, and Zheng Liu, 2014. Agglomeration and tax competition: evidence from China. Working paper.

Chen, Ye, Hongbin Li, and Li-An Zhou, 2005. Relative performance evaluation and the turnover 
of provincial leaders in China. Economics Letters 88, 421-425.

Choi, Eun Kyong, 2012. Patronage and performance: factors in the political mobility of provincial leaders in post-Deng China. The China Quarterly 212, 965-981.

Devereux, Michael, Ben Lockwood, and Michela Redoano, 2007. Horizontal and vertical indirect tax competition: theory and some evidence from the USA. Journal of Public Economics, 91, 451-479.

Devereux, Michael, Ben Lockwood, and Michela Redoano, 2008. Do countries compete over corporate tax rates? Journal of Public Economics 92, 1210-1235.

Eugster, Beatrix and Raphael Parchet, 2013. Culture and Taxes: Towards Identifying Tax Competition. Economics Working Paper Series 1339, University of St. Gallen, School of Economics and Political Science.

Fan Shenggen, Ravi Kanbur, Shang-Jin Wei and Xiaobo Zhang, 2013. The economics of China: successes and challenges. NBER Working Papers 19648.

Feltenstein, Andrew and Shigeru Iwata, 2005. Decentralization and macroeconomic performance in China: regional autonomy has its costs. Journal of Development Economics 76, 481- 501.

Fredriksson, Per G., John A. Listb, and Daneil L. Millime, 2004. Chasing the smokestack: strategic policymaking with multiple instruments. Regional Science and Urban Economics 34, 387-410.

Geys, Benny and Steffen Osterloh, 2013. Borders As Boundaries To Fiscal Policy Interactions? An Empirical Analysis Of Politicians Opinions On Rivals In The Competition For Firms. Journal of Regional Science 53, 583-606.

Hibbs, Douglas A, Jr, 1977. Political parties and macroeconomic policy. American Political Science Review 71, 1467-1487.

Hsieh, Chang-Tai and Peter J. Klenow, 2009. Misallocation and manufacturing TFP in China and India. The Quarterly Journal of Economics 124, 1403-1448.

Janeba, Eckhard and Steffen Osterloh, 2013. Tax and the city A theory of local tax competition. Journal of Public Economics 106, 89-100.

Jin, Hehui, Yingyi Qian, and Barry R. Weingast, 2005. Regional decentralization and fiscal incentives: federalism, Chinese style. Journal of Public Economics 89, 1719-1742.

Kanbur, Ravi and Xiaobo Zhang, 2005. Fifty years of regional inequality in China: a journey through central planning, reform, and openness. Review of Development Economics 9, 87-106.

Kelejian, Harry H. and Ingmar R. Prucha, 1998. A generalized spatial two-stage least squares procedure for estimating a spatial autoregressive model with autoregressive disturbance. Journal 
of Real Estate Finance and Economics 17:1, 99-121.

Lee, Lung-Fei, 2007. Identification and estimation of econometric models with group interactions, contextual factors and fixed effects. Journal of Econometrics 140, 333-374.

Lee, Lung-Fei and Jihai Yu, 2014. Efficient GMM estimation of spatial dynamic panel data models with fixed effects. Journal of Econometrics 180, 174-197.

Li, Hongbin and Li-An Zhou, 2005. Political turnover and economic performance: the incentive role of personnel control in China. Journal of Public Economics 89, 1743-1762.

Li, Yinan, 2012. China's political business cycle. Manuscript.

Liu, Yongzheng and Jorge Martinez-Vazquez, 2014. Inter-Jurisdictional Tax Competition In China. International Center for Public Policy Working Paper Series, at AYSPS, GSU paper1403.

Lin, Justin Yifu, and Zhiqiang Liu, 2000. Fiscal decentralization and economic growth in China. Economic Development and Cultural Change 49 (1): 1-21.

Long, Cheryl and Xiaobo Zhang, 2011. Cluster-based industrialization in China: financing and performance. Journal of International Economics 84, 112-123.

Maskin, Eric, Yingyi Qian, and Chenggang Xu, 2000. Incentives, scale economies, and organization forms. Review of Economic Studies 67, 359-378.

Montinola, Garbriella, Yingyi. Qian, and Barry R. Weingast, 1995. Federalism, Chinese style: the political basis for economic success in China. World Politics 48, 50-81.

Nickell, Stephen, 1981. Biases in dynamic models with fixed effects. Econometrica 49, 1417-1426.

Parchet, Raphael, 2014, Are Local Tax Rates Strategic Complements or Strategic Substitutes? IdEP Economic Papers 1407, USI Universit della Svizzera italiana.

Qian, Yingyi. and Barry R. Weingast, 1997. Federalism as a commitment to perserving market incentives. Journal of Economic Perspectives 11, 83-92.

Revelli, Federico and Per Tovmo, 2007. Revealed yardstick competition: local government efficiency patterns in Norway. Journal of Urban Economics 62, 121-134.

Qian, Yingyi. and Gerard Roland, 1998. Federalism and the soft budget constraint. American Economic Review 88, 1143-1162.

Song, Zheng Michael, Kjetil Storesletten and Fabrizio Zilibotti, 2011. Growing like China. American Economic Review 101, 196-233.

Whiting, Susan H., 2011. Power and Wealth in Rural China: The Political Economy of Institutional Change. Cambridge University Press.

Wilson, John D., 1999, Theories of Tax Competition. National Tax Journal 52: 269-304. 
Wu, Jing, Yongheng Deng, Jun Huang, Randall Morck, and Bernard Yeung, 2013. Incentives and outcomes: China's environmental policy. NBER working paper 18754.

$\mathrm{Xu}$, Chenggang, 2011. The fundamental institutions of China's reforms and development. Journal of Economic Literature 49, 1076-1151.

$\mathrm{Xu}$, Shousong, 2005. An Investigation of Tieben: A Death Report on a Private Steel Kindom.(in Chinese) South Daily Press.

Yao, Yi and Xiaobo Zhang, 2008. Race to the top and race to the bottom: tax competition in rural China. IFPRI Discussion Paper 00799.

Zhang, Tao and Hengfu Zou, 1998. Fiscal decentralization, public spending and economic growth in China. Journal of Public Economics 67: 221-240.

Zhang, Xiaobo, 2006. Fiscal decentralization and political centralization in China: implications for growth and inequality. Journal of Comparative Economics 34, 713-726.

Zheng, Xinye, Fanghua Li, Shunfeng Song and Yihua Yu, 2013. Central government's infrastructure investment across Chinese cities: a dynamic spatial panel data approach. China Economic Review 27, 264-276.

Zheng, Siqi, Matthew Kahn, Weizeng Sun and Danglun Luo, 2014. Incentives for China's urban mayors to mitigate pollution externalities: The role of the central government and public environmentalism. Regional Science and Urban Economics 47, 61-71.

Zhou, Li-An, 2009. Incentives and Governance: China's Local Governments. CENGAGE Learning. 